\title{
The winged helix transcription factor MFH1 is required for proliferation and patterning of paraxial mesoderm in the mouse embryo
}

\author{
Glenn E. Winnier, ${ }^{1}$ Linda Hargett, ${ }^{1,2}$ and Brigid L.M. Hogan ${ }^{1-3}$ \\ ${ }^{1}$ Department of Cell Biology and ${ }^{2}$ Howard Hughes Medical Institute, Vanderbilt University Medical School, \\ Nashville, Tennessee 37232-2175 USA
}

\begin{abstract}
The gene $m f h 1$, encoding a winged helix/forkhead domain transcription factor, is expressed in a dynamic pattern in paraxial and presomitic mesoderm and developing somites during mouse embryogenesis. Expression later becomes restricted to condensing mesenchyme of the vertebrae, head, limbs, and kidney. A targeted disruption of the gene was generated by homologous recombination in embryonic stem cells. Most homozygous mfh1 null embryos die prenatally but some survive to birth, with multiple craniofacial and vertebral column defects. Using molecular markers, we show that the initial formation and patterning of somites occurs normally in mutants. Differentiation of sclerotome-derived cells also appears unaffected, although a reduction of the level of some markers [e.g., mtwist, mf1, scleraxis, and $\alpha 1$ (II) collagen] is seen in the anterior of homozygous mutants. The most significant difference, however, is a marked reduction in the proliferation of sclerotome-derived cells, as judged by BrdU incorporation. This proliferation defect was also seen in micromass cultures of somite-derived cells treated with transforming growth factor $\beta 1$ and fibroblast growth factors. Our findings establish a requirement for a winged helix/forkhead domain transcription factor in the development of the paraxial mesoderm. A model is proposed for the role of $m f h 1$ in regulating the proliferation and differentiation of cell lineages giving rise to the axial skeleton and skull.
\end{abstract}

[Key Words: Mouse embryogenesis; winged helix, transcription factor; proliferation; patterning; paraxial mesoderm]

Received December 11, 1996; revised version accepted February 28, 1997.

A major challenge in vertebrate embryology is to elucidate the mechanisms by which mesodermal cells acquire and achieve their wide-ranging developmental fates. Mesoderm specification is tightly linked with the process of gastrulation, in which epiblast cells enter the primitive streak and become allocated to different mesoderm populations: Midline cells give rise to the prechordal plate and notochord, paraxial mesoderm cells generate the unsegmented mesoderm of the head and the paired somites on either side of the neural tube, and the lateral mesoderm forms the splanchnopleure and somatopleure. The paraxial mesoderm contributes extensively to many adult tissues, including most of the axial skeleton, the muscles of the trunk, and the dermis of the skin, as well as to specific skull bones and muscles of the head and neck. Mutations that affect paraxial mesoderm development are therefore likely to have considerable effects on body form (for review, see Tam and Trainor 1994).

The formation of somites begins at the rostral end of

${ }^{3}$ Corresponding author.

E-MAIL brigid.hogan@mcmail.vanderbilt.edu; FAX (615) 343-2033. the presomitic mesoderm, a population of multipotent cells generated from either the primitive streak or the tail bud mesenchyme. Fate mapping and orthotopic transplantation studies in the mouse have shown that cells in the primitive streak of 7.5 and 9.5 days post coitum (dpc) embryos tend to colonize the more anterior somites (up to about somite 21), whereas tail bud mesenchyme normally contributes to posterior somites (Beddington 1981, 1982; Tam and Trainor 1994; for review, see Smith et al. 1994). In either case, newly formed somites are generated by the compaction and epithelialization of loosely associated mesenchymal units known as somitomeres, and become patterned along their anteroposterior, dorsoventral, and mediolateral axes. The ventromedial region of the somite forms the sclerotome, whereas the dorsolateral domain gives rise to the epithelial dermomyotome. Recent in vitro studies have provided evidence that dorsoventral and mediolateral patterning are under the influence of local signaling molecules from the notochord, surface ectoderm, neural tube, and lateral mesoderm (Fan and Tessier-Lavigne 1994; Fan et al. 1995; Pourquie et al. 1995, 1996).

Following induction by signals from the notochord 
and ventral neural tube, sclerotome cells proliferate and migrate toward the notochord, giving rise to a medioventral domain that will form the vertebral body and intervertebral discs, a ventrolateral domain that forms the ribs, and a ventromedial domain that gives rise to the neural arches and the pedicles (Verbout 1985; Johnson 1986; Christ and Ordahl 1995; Pourquie et al. 1996). Lineage tracing and orthotopical transplantation experiments in chick embryos have also shown that within each developing somite, sclerotomal cells segregate into rostral and caudal domains, expressing different genes and with looser and more compact cell densities, respectively (Stern and Keynes 1987; Norris et al. 1989; Ranscht and BronnerFraser 1991). Moreover, cell labeling studies have shown that each vertebra is derived from the caudal half of one somite, and the rostral half of the posteriorly adjacent somite (Bagnall 1992), a finding consistent with the theory of sclerotomal resegmentation proposed by Remak in 1855 (Verbout 1985; Bagnall 1992).

Intense genetic and molecular analysis has led to the identification of many genes expressed in subpopulations of the dermomyotome of the somite and required for the development of specific muscle groups derived from them (Bober et al. 1994; Buffinger and Stackdale 1994; Olson and Klein 1994; Christ and Ordahl 1995; Pourquie et al. 1995, 1996). However, much less is known about the genes regulating the patterning of the sclerotome, and the proliferation and the differentiation of the various cell types derived from it. The large number of mouse mutants with vertebral abnormalities promises to be an invaluable resource for investigating this problem (Johnson 1986; Theiler 1989; Balling et al. 1992; Dietrich et al. 1993). One of the first mutants to be studied at the molecular level was undulated $(U n)$, caused by a point mutation in the pax 1 gene, encoding a paired domain/homeodomain transcription factor. The mutant phenotype is characterized by malformation of vertebral bodies and intervertebral discs and the proximal ribs (Koseki et al. 1993; Wallin et al. 1994; Dietrich and Gruss 1995). This phenotype, and in vitro studies in with embryonic tissue, have provided strong evidence that pax1 is required for ventral sclerotome differentiation during mouse development (Fan and Tessier-Lavigne 1994; Fan et al. 1995). The functional analysis of other genes expressed in the sclerotome, including scleraxis and paraxis, which encode basic helix-loop-helix (bHLH) transcription factors (Burgess et al. 1995; Cserjes et al. 1995), will add greatly to our understanding of vertebral patterning.

Previous studies from this laboratory and others have identified a number of mouse genes in the winged helix/ forkhead domain superfamily of transcription factors. In particular, the expression patterns of $m f h 1, m f 1(f k h 1)$, $m f 2$, and $m f 3(f k h 5)$ suggest that they are involved in paraxial mesoderm and somite patterning and differentiation during mouse development (Kaestner et al. 1993, 1996a,b; Miura et al. 1993; Sasaki and Hogan 1993; Kaufman and Knochel 1996). Here we focus on mfh1, which is initally expressed in a dynamic pattern in the presomitic mesoderm, somites, and cephalic mesoderm. As development proceeds, $m f h 1$ transcripts are localized to condensing mesenchymal lineages of the vertebral column, nasal process, limbs, and the developing kidney (Miura et al. 1993; Kaestner et al. 1996a).

To investigate the role of $m f h 1$, we have generated a null allele by homologous recombination in embryonic stem (ES) cells. Most mfh1 homozygous null embryos die prenatally, beginning $\sim 13.5 \mathrm{dpc}$. However, mutants that survive to later stages exhibit multiple craniofacial and vertebral defects that result from the absence or malformation of skeletal elements primarily derived from cephalic and somitic mesoderm. Analysis of early $m f h 1$ mutant embryos reveals a reduction in the proliferation and possibly also the differentiation of sclerotome-derived cell lineages. These findings suggest that $m f h 1$ encodes a transcription factor that is required for the proliferation of a subset of paraxial mesoderm precursor cells involved in the formation of the axial skeleton and skull.

\section{Results}

Localization of mfhl RNA during mouse embryogenesis

$m$ fh1 expression is first detected by whole-mount in situ hybridization at $7.0 \mathrm{dpc}$ in non-notochordal mesoderm surrounding the node and notochord (data not shown). Figure $1 \mathrm{~A}$ shows expression of $m f h 1$ in these locations at $7.5 \mathrm{dpc}$. By $8.5 \mathrm{dpc}, \mathrm{mfh} 1 \mathrm{RNA}$ is detected in the anterior presomitic mesoderm adjacent to the youngest somites, in the somites, and in the cephalic mesoderm (Fig. 1B; data not shown). Later, at $9.5-10.5 \mathrm{dpc}, \mathrm{mfh} 1$ is still expressed in the presomitic mesoderm and epithelial somites. However, as the somite differentiates, overall $m f h 1$ expression levels decrease, so that transcripts are always highest in the most caudal or youngest somites and the anterior presomitic mesoderm (Fig. 1C,D). Moreover, the localization of transcripts is very dynamic; initially, expression is detected throughout the epithelial somites, but later becomes progressively restricted, first to the dermomyotome, then to the dorsomedial and dorsolateral myotomal precursors and sclerotome, and finally to the sclerotome of differentiated somites (Fig. 1 G-I; summarized in Fig. 9).

By $10.5 \mathrm{dpc}$, mfh1 expression is detected in the branchial arches and mesenchymal cells surrounding the eye (Fig. 1D,E). At $11.5 \mathrm{dpc}$, transcripts are present in the nasal processes, the eye region, branchial arches, blood vessels, endocardium, and mesenchymal condensations that will form the future appendicular and axial skeleton (Fig. 1E,F; data not shown). In later embryos, sites of expression include the developing otic capsule, joints of the digits, and the mesenchyme of the kidney (Miura et al. 1993; Kaestner et al. 1996a; data not shown).

\section{Targeted disruption of the mouse $\mathrm{mfh} 1$ gene}

To investigate $m f h 1$ function, a null allele was generated by homologous recombination in ES cells. Mapping of 
Figure 1. Localization of $m f h 1$ transcripts in 7.5to 11.5 -dpc embryos. (A) Frontal view of a 7.5-dpc embryo showing expression in paraxial mesoderm, but not in the node or notochord. $(B)$ Lateral view of a 8.5-dpc embryo, showing strong expression in the presomitic mesoderm, somites, and cephalic mesoderm. (C) In 9.5-dpc embryos, $m f h 1$ transcripts are now seen in the region surrounding the developing eye and in the second and third branchial arches, and expression is maintained in the presomitic mesoderm, somites, and cephalic mesoderm. The white arrowhead indicates the expression of $m f h 1$ in the denser posterior region of the somite. $(D)$ By 10.5 $\mathrm{dpc}$, expression is reduced in anterior somites, but remains high in the posterior somites and tail bud. $(E)$ External view of an hemisected 11.5-dpc embryo, showing expression in the condensing mesenchyme of the vertebral column, forelimbs, and hindlimbs, and in the branchial arches. $(F)$ Internal view of the same embryo, showing strong expression in the nasal region and blood vessels. $(G-I)$ Localization of $m f h 1$ transcripts in the maturing somite by section in situ hybridization. The level of each section is shown in $C$ and $D$. $(G)$ Expression is detected throughout the epithelial somite. $(H)$ Expression is reduced in the dermomyotome, and persists in the dorsomedial and dorsolateral dermomyotome (arrows). (I) In differentiated somites, expression is restricted to the sclerotome. No expression is detected in the myotome or dermotome. Bars: $\langle G| 50 \mu \mathrm{m}_{i}\{H, I\}$, $60 \mu \mathrm{m}$. (b) Branchial arch; (cm) cephalic mesoderm $_{i}(\mathrm{dm}$ ) dermomyotome; (d) dermotome; (es) epithelial somite; (fb) forelimb; (h) heart; (hb) hindlimb; (mcv) mesenchymal condensation of vertebrae; $(\mathrm{m})$ myotome; $(\mathrm{n})$ node; $(\mathrm{p})$ presomitic mesoderm; (sc) sclerotome; (s) somites; (1) lower jaw.
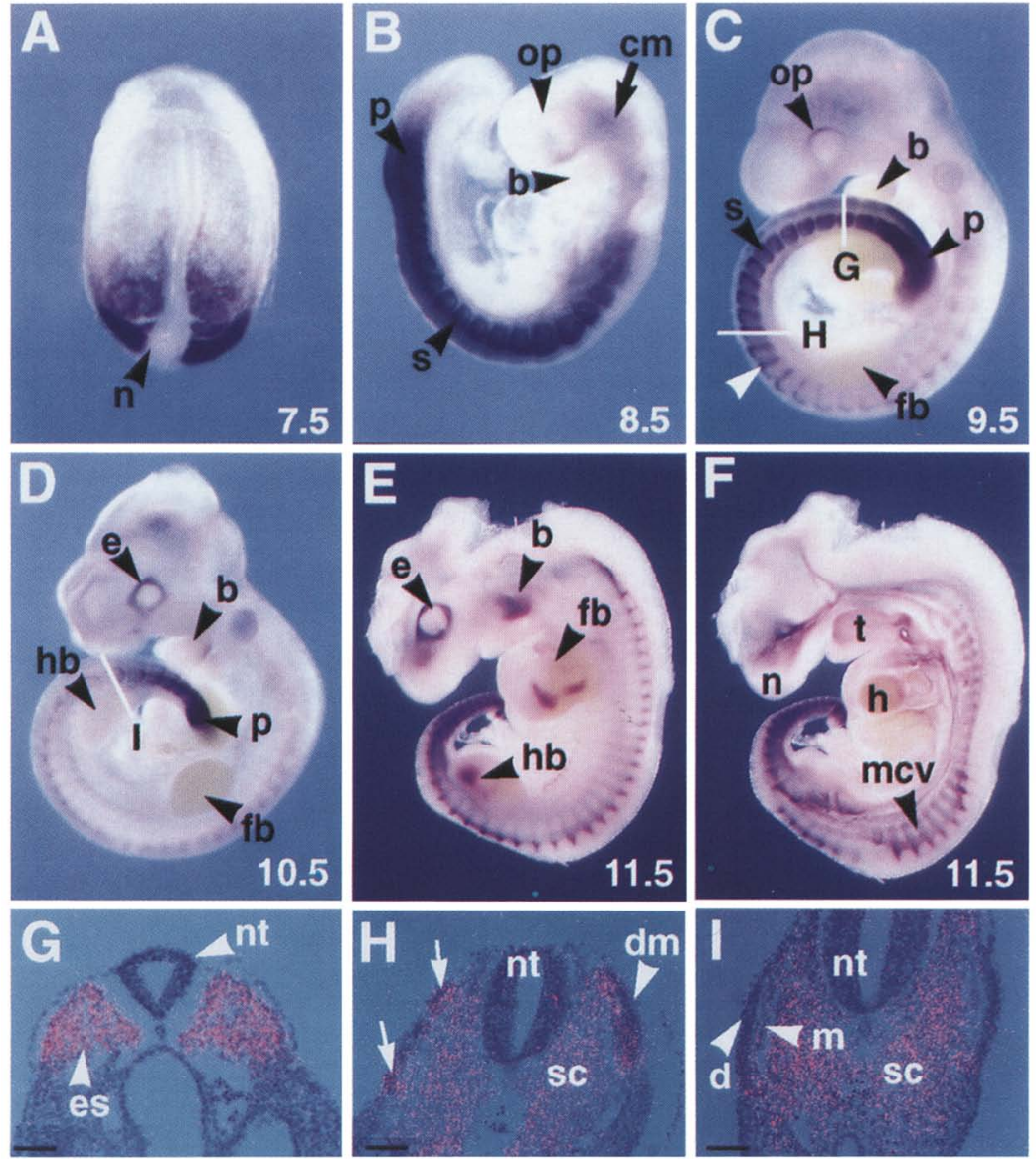

the $m f h 1$ locus reveals a single exon that encodes a 2.7$\mathrm{kb}$ transcript including the forkhead domain (Miura et al. 1993; Kaestner et al. 1996a) (Fig. 2). The targeting strategy (Fig. 2) was designed to delete the entire protein coding region. Two independently targeted ES clones were injected into $\mathrm{C} 57 \mathrm{BL} / 6$ blastocysts, chimeras were obtained, and heterozygotes for the $m f h 1^{t m 1}$ mutant allele were generated. These appeared normal and were fertile. However, following intercrossing of $m f h 1^{t m 1}$ heterozygotes, only six $m f h 1(-/-)$ pups were identified (Table 1), and these all died within hours of birth. Genotyping of embryos before birth demonstrated that the majority of homozygous mutants did not survive beyond $13.5 \mathrm{dpc}$ (Table 1), showing that the $m f h 1$ disruption is a recessive embryonic lethal mutation.

In confirmation of the deletion of the mfh 1 allele, whole-mount in situ hybridization with the full-length mfh1 cDNA showed that no $m f h 1$ transcripts were detected in the homozygous mutant embryos /data not shown). To investigate whether deletion of $m f h 1$ had detrimental effects on the downstream winged helix gene, $f k h 6$, we examined the expression of this gene by section in situ hybridization (data not shown). We observed the normal level and pattern of expression of fkh6 RNA in the mfh 1 mutant embryos, suggesting that the mutant phenotype results from the loss of $m f h 1$.

\section{Embryonic lethality of $\mathrm{mfh} 1$ homozygous null embryos}

From 8.5 to $12.5 \mathrm{dpc}, m f h 1$ homozygous null embryos are comparable in size to wild-type $+1+$ or +1 - littermates. However, $42 \%$ of the mutant embryos exhibited a severely crooked neural tube and irregular somites. Frequently, large pools of blood were found at multiple sites surrounding the hindbrain and spinal cord, suggesting discontinuities in the circulatory system. At $11.5 \mathrm{dpc}$, all mutant embryos had beating hearts, but from 12.5 to $13.5 \mathrm{dpc}$ most homozygous null embryos were dying and being resorbed.

Discontinuities in the cardiovascular system were examined by histological analysis on the heart and major vessels, revealing no abnormal morphology compared with wild-type littermates (data not shown). To assess 


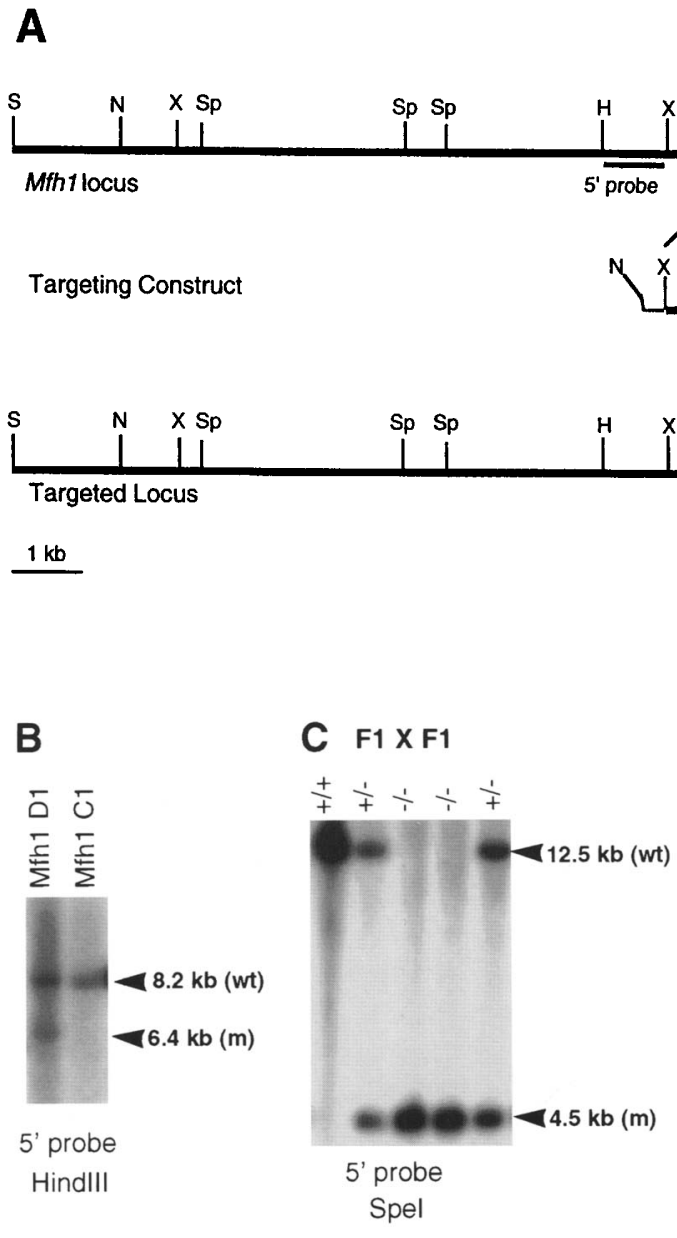

Figure 2. Targeted disruption of the $m f h 1$ gene. (A, top line) Genomic organization of $m f h 1$ showing one exon with protein coding (black box) and untranslated regions (white boxes). The winged helix domain is represented by a hatched box. (A, middle line) The targeting vector consists of the PGKneo ${ }^{r}$ cassette (stippled box) flanked by the 1.2-kb $5^{\prime}$ homology (XhoI-XhoI fragment) and 2.9-kb 3' homology arms (EcoRI-EcoRI fragment). The 3' PGK-thymidine kinase cassette (solid box) is located at the $3^{\prime}$ end. (A, bottom line) Structure of the targeted locus. The entire protein coding region and the majority of the untranslated sequences of the $m f h 1$ locus were replaced by the the neo ${ }^{r}$ cassette. (B) Homologous recombinants were detected using a $5^{\prime}$ probe $11.3-\mathrm{kb}$ HindIIIXhoI fragment) on Southern blots digested with HindIII. (wt) Wild-type locus; $(\mathrm{m})$ targeted locus. (C) Male and female $\mathrm{F}_{1}$ mice were produced by mating Black Swiss females with chimeric males. Homozygous embryos were produced from an intercross between $F_{1}$ females and males. Genotyping of embryo was performed by digestion of genomic DNA with SpeI and hybridization with the $5^{\prime}$ probe. The wild-type and targeted locus generate $12.5-\mathrm{kb}$ and $4.5-\mathrm{kb}$ hybridizing fragments, respectively. (E) EcoRI; (H) HindIII; (N) NcoI; (Nt) NotI; (P) PstI; (S) SalI; (Sp) SpeI; (X) XhoI. the overall development of the vascular system, wholemount immunohistochemistry was performed between 8.5 and $12.5 \mathrm{dpc}$ with a monoclonal antibody that detects

Table 1. Genotypes of offspring from $\mathrm{mfh} 1^{\mathrm{tm} 1}+/-$ heterozygote matings

\begin{tabular}{lccccc}
\hline & & \multicolumn{4}{c}{ Genotype $^{\mathrm{a}}$} \\
\cline { 3 - 6 } Age $(\mathrm{dpc})$ & Total & $+/+$ & $+/-$ & $-/-$ & N.D. \\
\hline 8.5 & 59 & 19 & 23 & 13 & 4 \\
9.5 & 173 & 38 & 76 & 45 & 14 \\
10.5 & 205 & 49 & 90 & $56(6)$ & $10(2)$ \\
11.5 & 107 & 22 & 51 & $26(3)$ & $8(4)$ \\
12.5 & 142 & 45 & 66 & $30(5)$ & 1 \\
13.5 & 77 & 23 & 39 & 11 & $4(4)$ \\
14.5 & 28 & 3 & 13 & $3(2)$ & $9(6)$ \\
16.5 & 39 & 12 & 17 & $8(6)$ & $2(2)$ \\
17.5 & 26 & 6 & 14 & 4 & $2(2)$ \\
19.5 & 28 & 8 & 15 & 1 & $4(4)$ \\
Total & 884 & 225 & 404 & 197 & 58 \\
& & $(25 \%)$ & $(46 \%)$ & $(22 \%)$ & $(7 \%)$ \\
Newborn & 173 & 73 & 94 & 6 & \\
& & $(42 \%)$ & $(55 \%)$ & $(3 \%)$ & \\
\hline
\end{tabular}

${ }^{\mathrm{a}}$ Numbers in parentheses indicate embryos being resorbed.
PECAM-1 (CD31) (platelet endothelial cell adhesion molecule-1). This marker is first expressed by early endothelial cells within the yolk sac, and subsequently by cells throughout the embryonic vascular system (Baldwin et al. 1994). As shown in Figure 3, the expression of PECAM-1 was not altered significantly in the majority of the $m f h 1^{t m 1}$ null embryos (Fig. 3C,D). However, a loss of intersegmental blood vessels was observed in the thoracic and cervical regions of more severely affected mutants (Fig. 3B). Histological examination of $m f h 1(-/-)$ embryos revealed no significant disorganization of the mesenchyme surrounding the blood vessels (data not shown). Although some defects were seen in more severely affected younger mutants, we cannot exclude additional effects of the mutation on blood vessel integrity, permeability, or other properties as the cause of death in more advanced mutants.

\section{mfh1 -/- mutants have skeletal abnormalities}

Skeletal preparations were made from $m f h 1-/-$ neonates $(n=6)$ and $16.5 \mathrm{dpc}$ embryos $(n=2)$, and compared with wild-type littermates. The skeletal abnormalities observed are summarized in Table 2 . In all mutants, craniofacial, and vertebral defects, and rib fusions were ob- 
Table 2. Summary of skeletal defects observed in $\mathrm{mfh}^{\mathrm{tm} l}$ newborn mutants

\begin{tabular}{lll}
\hline Structure & \multicolumn{1}{c}{ Defect } & Primary origin \\
\hline Supraocciptial & absent & cephalic \\
Basisphenoid & absent & cephalic \\
Phesphenoid & absent & cephalic \\
Gonial $^{\star}$ & malformed & cephalic \\
Incus/stapes $^{\text {a }}$ & absent & cephalic \\
Exoccipitial $_{\text {Basiooccipitial }}$ & reduced & somitic \\
Vertebrae & reduced & somitic \\
Ribs & malformed & somitic \\
Xiphoid & fused/absent & somitic \\
Mandibles & malformed & somitic \\
Interparietal & malformed & neural crest \\
Squamosal & reduced & neural crest \\
Palatine & malformed & neural crest \\
Tympanic & absent & neural crest \\
\hline
\end{tabular}

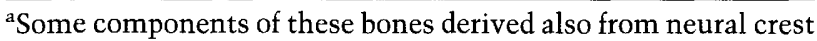
cells.

served, but the appendicular skeleton, including digit patterning, was normal.

\section{Craniofacial skeletal elements are altered or absent in neonatal mfh $1-/-$ mutant mice}

In the $m f h 1-/-$ embryos that were born /and were therefore the least affected phenotypically), no trace of the supraoccipital bone was observed (Fig. 4A,B), and the exoccipital, basioccipital, interparietal, and squamosal bones were misshapen and reduced. At the base of the skull, the pterygoid bone and basisphenoid bone were reduced, and the palatine and presphenoid bones were largely missing (Fig. 4C), resulting in a cleft palate. The mandibles were also slightly shortened. No apparent phenotypic differences were observed in the nasal septum and frontal bones of the skull (Fig. $4 \mathrm{G}, \mathrm{H}$ ).

Besides the craniofacial abnormalities, $m f h 1-/-$ neonates display several defects in the ossicles of the middle ear, the malleus, incus, and stapes, structures that arise from cephalic mesoderm and neural crest (Novack 1993). The malleus, formed from Meckel's cartilage, is misshapen in the $m f h 1-/-$ mutants (data not shown). The incus, which is derived from the proximal end of the palatoquadrate cartilage (Novack 1993) and forms a separate cartilaginous body attached to the head of the malleus and stapes, was missing. The stapes was absent, whereas the gonial bone was malformed and failed to properly attach to the tympanic ring. The tympanic ring was also reduced (data not shown).

To identify the developmental processes affected in the more advanced homozygous mutants, skeletons from embryos at an earlier stage of development (16.5 dpc) were examined. As shown in Figure 4, the forming occipital bones and otic capsule cartilage were present, but reduced in size (Fig. 4E,F), and the mandible and Meckel's cartilage were reduced and misshapen in mutants (Fig. 4D-F) compared with wild-type embryos. At the base of the skull, the basisphenoid bone was reduced, and the palatine processes and presphenoid bone were also absent (Fig. 4C).

The abnormalities described above were fully penetrant in the older surviving mutant embryos. Moreover, the craniofacial structures affected were limited to a specific set of skeletal elements, namely, those derived from the cephalic and somitic mesoderm, and only involved to a lesser, and probably secondary, extent structures arising from cranial neural crest populations.

\section{Vertebral defects in mfhl mutant mice}

As summarized in Figure 5, skeletal analysis of those mfh1 -/- homozygotes surviving to $16.5 \mathrm{dpc}$ and birth revealed consistent abnormalities in both the dorsal and ventral aspects of the vertebrae. These abnormalities were more striking in the more anterior vertebrae, particularly in the cervical (C2-C7) and upper thoracic (T1) region, where the ossification centers of the centrum are absent (Fig. 5, see especially newborn C4). In contrast, in the lower thoracic, lumbar, and sacral vertebrae, these ossification centers form, but fail to fuse medially, giving rise to split centra (Fig. 5, e.g., newborn T13). Defects were also observed in the neural arches, which were misshapen and exhibited a reduction in ossification when compared with wild-type siblings (Fig. 5, e.g., newborn $\mathrm{L} 1$ and S1). Examination of the rib cage of $m f h 1-/-$ mice revealed multiple rib fusions and loss of ribs (Fig. 4I,J). These defects were observed at a high frequency in the

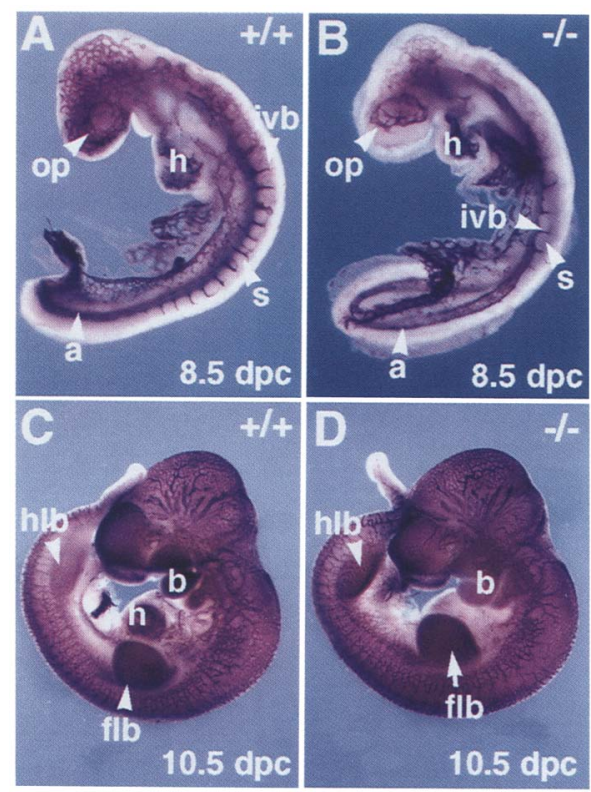

Figure 3. Expression of PECAM-1/CD-31 protein by wholemount immunohistochemistry in wild-type and mutant embryos. $(A, B)$ Localization in 8.5-dpc wild-type and mutant embryos, showing expression in the heart $(\mathrm{h}\rangle$, dorsal aorta $|\mathrm{a}|$, and throughout the vascular system. Expression at $10.5 \mathrm{dpc}$, in wildtype $(C)$ and mutant $(D)$ embryos. (b) Branchial arches; (flb) forelimb bud; (hlb) hindlimb bud; (ivb) intersegmental blood vessel; (op) optic placode; (s) somites. 

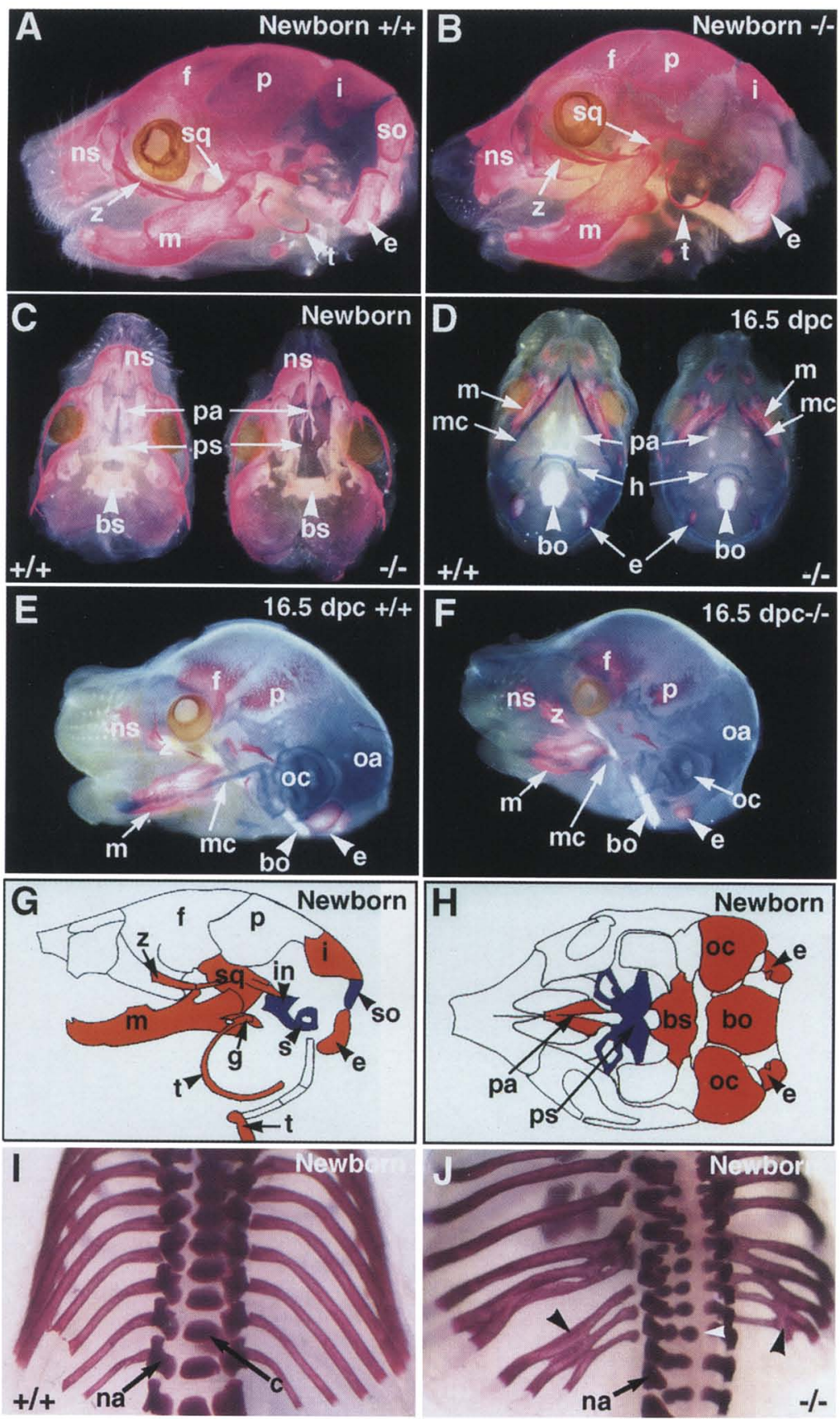

Figure 4. Skull phenotypes in wild-type and $m f h 1$ $-/$ - mice. The skeletons of newborn and 16.5 -dpc embryos were stained with alcian blue and alizarin red and cleared in alkali and glycerol. $(A, B)$ Lateral views of newborn wild-type and $m f h 1-/-$ skulls. The absence of the supraoccipital (so) and bones of the otic capsule and the malformation of the exoccipital (e) and interparietal (i) bones are apparent in the mutant skull. $(C)$ Ventral views of newborn skulls. The bones of the lower jaw have been removed. A cleft palate is formed by the loss of the palatine bones (pa) and presphenoid bones (ps) in the mutants. (D) Ventral view of 16.5 -dpc, wildtype, and $m f h 1-/-$ skulls showing the absence of the palatine process (pa) leaving an open view of the nasal cavity. $(E, F)$ Lateral views of wild-type and $m f h 1-1-16.5$-dpc skulls, showing a reduction in cartilage staining in the optic capsule (oc), and the occipital arches (oa). In addition, the exoccipital bone (e) of the $m f h 1$ mutant $(-/-)$ is reduced. $\{G, H)$ Schematic of the lateral and ventral views of wildtype newborn skull. Skeletal elements that are absent in the mutants are shaded in blue; elements which are reduced or malformed are represented in red. $(I, I)$ Dorsal view of wild-type and mutant newborn rib cages, showing multiple rib fusions (black arrowheads) and split centra (white arrowhead). (bo) Basioccipital bone; (bs) basisphenoid bone; (c) centrum; (f) frontal bone; (g) gonial bone; (h) hyoid bone; (in) incus; (m) mandible; (mc) Meckel's cartilage; (na) neural arches; (ns) nasal septum; (p) parietal bone; (ps) presphenoid bone; (oc) otic capsule; (sq) squamosal bone; (s) stapes; ( $t$ ) tympanic ring; $(z)$ zygomatic bone. lower thoracic regions (Fig. 4J). In addition, the ribs were often fused directly to the neural arches (data not shown). Examination of 16.5 -dpc skeletons revealed abnormalities similar to those observed in the $m f h 1-1-$ neonates.

\section{Molecular analysis of $\mathrm{mfh} \mathrm{1}^{\mathrm{tm} 1}$ null mutants}

The reduction, malformation, or absence of specific skeletal elements observed in the more advanced $m f h 1 \mathrm{mu}-$ tants described above most likely involve defects in the growth, differentiation, and/or condensation of cartilage precursor populations earlier in development. To investigate these possibilities, whole-mount and section in situ hybridization were performed on mutant embryos between 8.5 and $12.5 \mathrm{dpc}$, with markers of mesodermal patterning and differentiation (for review, see Tam and Trainor 1994).

We first examined by whole-mount in situ hybridization the expression of $m f 1(f k h 1)$, a closely related winged helix/forkhead gene. $m f h 1$ and $m f 1(f k h 1)$ are normally expressed in overlapping sites in the presomitic mesoderm, somites, and head mesenchyme and in nonoverlapping sites in the branchial arches (Sasaki 


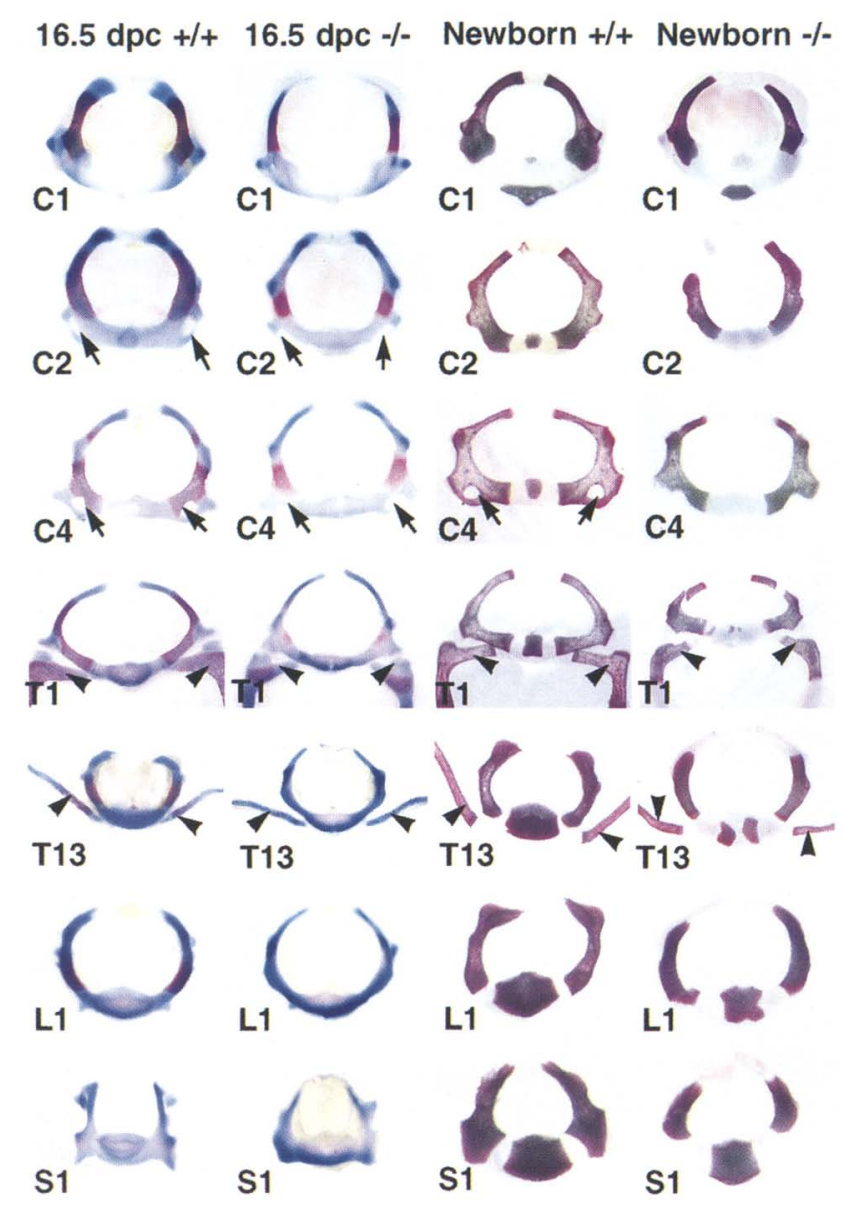

Figure 5. Morphology of the vertebral column. Cervical vertebrae $(\mathrm{C} 1, \mathrm{C} 2, \mathrm{C} 4)$, thoracic $(\mathrm{T} 1, \mathrm{~T} 13)$, lumber (L1), and sacral (S1) from wild-type and $\mathrm{mfh} 1-/$ - embryos at $16.5 \mathrm{dpc}$ and at birth show defects in the neural arches, centrum, and the foramen transversum (arrows). Arrowheads show the position of the ribs in the thoracic vertebrae. No ossification centers of the centrum are observed in the cervical $(\mathrm{C} 2, \mathrm{C} 4)$ and first thoracic vertebrae of the $m f h 1-/-$ newborns.

and Hogan 1993), raising the possibility that $m f 1$ may partially compensate for the absence of the $m f h 1$ gene product. To examine early mesodermal patterning, we also analyzed the expression of murine twist, which encodes a bHLH gene expressed in the sclerotome, cephalic mesoderm, and the mesoderm of the somatopleure and limb buds (Wolf et al. 1991; Stoetzel et al. 1995). In $\mathrm{mfh} 1$ -/- embryos, $m f 1$ and twist were expressed in normal patterns, but at a slightly reduced level in the somites, consistent with a reduction in the size of the expressing cell population rather than a change in level per cell (Fig. 6A-D).

To investigate the transition of the mesenchymal presomitic mesoderm to an epithelial somite and the anterioposterior patterning of the somite, five markers were examined: fibroblast growth factor receptor 1 (fgfr1), notch1, mf3(fkh5), paraxis, and mox1. fgfR1 and notch1 are normally expressed in the anterior portion of pre- somitic mesoderm and the rostral half of the newly formed somites (Reaume et al. 1992; Williams et al. 1995). The winged helix gene $m f 3(f k h 5)$ is expressed in the presomitic mesoderm, dorsomedial region of the somite, and neural tube (Kaestner et al. 1996a,b; data not shown). The normal pattern of expression of these markers and histological examination of mutants /data not shown) suggests that $m f h 1$ is not required for the segmentation of the paraxial mesoderm or for somite epithelization. To further examine the anterioposterior patterning of the somite, we analyzed the expression of paraxis and mox1. paraxis, which encodes a bHLH protein, is expressed at high levels throughout the newly formed somite. As the somite differentiates, expression in the myotome is down-regulated, whereas expression persists in the dermotome and sclerotome (Burgess et al. 1995). mox 1 is a homeobox gene normally expressed in the presomitic mesoderm, dermomyotome, sclerotome, and lateral plate mesoderm and is differentially expressed in the anterior halves of the somite /Candia et al. 1992; data not shown). From the normal expression of paraxis and mox 1 in the mfh1 homozygous null embryos, we conclude that the subdivision into the anterior and posterior halves and the differentiation of the somite occurs normally. These findings provide evidence that the formation of presomitic mesoderm and epithelial somites, and their early patterning (i.e., dorsomedial, dorsoventral, and anterioposterior), is essentially normal in the $m f h 1^{t m 1}$ mutants.

Because $m f h 1$ is transiently expressed in the myotome, myoD and myogenin expression were examined to assess the formation and differentiation of muscle precursors in the somite. At $10.5 \mathrm{dpc}$, myoD and myogenin are markers of differentiated myoblasts in the limb buds as well as in the axial musculature. As seen in Figure 6, $\mathrm{E}$ and $\mathrm{F}$, the somites and myocytes of the mutant embryos at $10.5 \mathrm{dpc}$ express myoD and myogenin normally, even in severely affected embryos, which were identified by the crooked neural tube (data not shown). This demonstrates that myotomal cells form at the appropriate developmental time in the mutant embryos.

To identify the different cell lineages in the sclerotome and to investigate the differentiation of the sclerotome, we analyzed the expression of pax1 and pax 9 . pax 1 and pax 9 transcripts are normally restricted to the medioventral region of the sclerotome of differentiating somites between $9.5 \mathrm{dpc}$ and $10.5 \mathrm{dpc}$ (Deutsch et al. 1988; Wallin et al. 1994; Neubuser et al. 1995). In 10.5dpc mfh1 mutant embryos, pax1 expression is not altered in the sclerotome (data not shown). At $12.5 \mathrm{dpc}$, pax1 is normally expressed in the mesenchyme surrounding the vertebral body primordia (Fig. 6G) and is down-regulated as the mesenchymal condensations differentiate into prechondroblasts (Deutsch et al. 1988; Wallin et al. 1994). At $12.5 \mathrm{dpc}$, expression of pax1 in the posterior vertebrae of mutant embryos is normal. In contrast, the condensing mesenchymal cells of the anterior vertebrae express pax1 in a dumbbell-like pattern surrounding the notochord (Fig. 6H). The mutant notochord, in turn, is surrounded by irregular condensations 


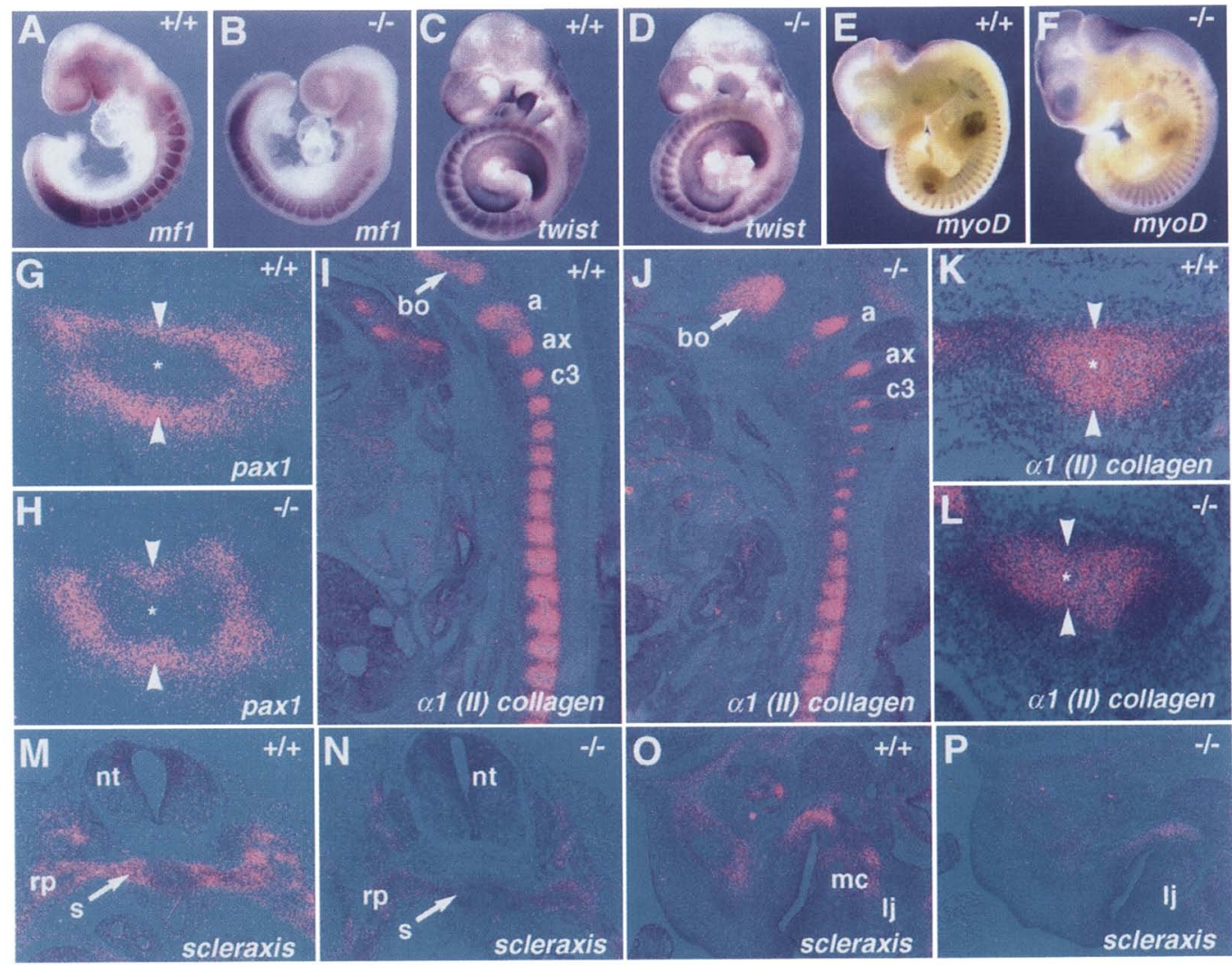

Figure 6. In situ hybridization analysis of mesodermal and sclerotomal markers in wild-type (A,C,E, G,I,K,M,O) and mfh1 mutant $(\mathrm{B}, \mathrm{D}, \mathrm{F}, \mathrm{H}, \mathrm{J}, \mathrm{L}, \mathrm{N}, \mathrm{P})$ embryos between 8.5 and $12.5 \mathrm{dpc} .(A, B)$ Lateral views of wild-type and $m f h 1-/-8.5$-dpc embryos, both showing strong expression of $m f 1$ in the presomitic mesoderm, somites, branchial arches, and cephalic mesoderm. $(C, D)$ Expression of murine twist in 9.5-dpc wild-type and mutant embryos. The $m f h 1-/-$ embryo expresses twist in the cephalic and branchial neural crest and in some derivatives of the sclerotome, somatopleura, and the limb buds $(E, F)$. The myogenic gene myoD is highly localized to the differentiating muscle precursor cells in both the wild-type $(E)$ and $m f h 1-/-(F)$ 10.5-dpc embryos. $(G, H)$ pax 1 expression in the sclerotome around the notochord. $(G)$ In the wild type, pax1 is expressed in sclerotomal cells prior to differentiation into chondroblasts. $(H)$ pax 1 transcripts are detected in a dumbbell-like pattern in the cervical vertebrate of $m f h 1-/-$ embryos. White arrowheads marks the midline of the sclerotome. (I,J) Expression of iga1(II) collagen in the vertebral column. (J) $\alpha 1$ (II) collagen expression is reduced in the cervical and upper thoracic vertebrae, and altered in the basioccipital region (bo) of the $\mathrm{mfh} 1 \mathrm{mutants}$. (K) $\alpha 1$ (II) collagen is expressed normally in the sclerotomal mesenchyme prior to chondrogenesis. $(L) \alpha 1(I I)$ collagen transcripts are asymmetrically distributed around the notochord in the $m f h 1-/$ - sclerotome. This pattern is the reciprocal of that seen in $H$ for pax 1 , suggesting the transition from condensing sclerotome to chondroblasts is normal. $(M, N)$ scleraxis expression in the sclerotome of 12.5 -dpc embryos. $(M)$ scleraxis is normally expressed in the lateral regions of the rostral sclerotome and prechondroblasts of the developing vertebrae and rib primordia. $(N)$ In $m f h 1-/$ - embryos, scleraxis expression is reduced in the lateral sclerotome and in the developing vertebrae. $\{O, P \mid$ Expression of scleraxis in the nasal and lower jaw region. $(P)$ scleraxis expression is reduced throughout the nasal region and lower jaw of 12.5-dpc mutant embryos. Bars: $(A, B) 65 \mu \mathrm{m} ;(C, D, I, J) 200 \mu \mathrm{m} ;(E, F) 60 \mu \mathrm{m} ;(G, H) 140 \mu \mathrm{m}$. (a) Atlas; (ax) axis; (li) lower jaw; (mc Meckel's cartilage; $\left(^{*}\right)$ notochord; $(\mathrm{nt})$ neural tube; $(\mathrm{rp})$ rib primordia; $(\mathrm{s})$ sclerotome; $(\mathrm{c} 3)$ third cervical vertebra.

of pax1-negative cells, presumably prechondroblasts. In contrast, the normal pattern of expression of pax 9 in the sclerotome and the anlagen of the intervertebral and vertebral bodies at $12.5 \mathrm{dpc}$ was observed in $m f h 1$ mutants (data not shown). These results suggest that formation and differentiation of sclerotomal cell lineages are essentially normal in the $m f h 1^{t m 1}$ mutants, and that the malformations of the vertebrae and the altered pax1 expression result from either a reduction in the number and density of cells surrounding the notochord and/or from abnormalities in sclerotomal cell migration.

To investigate the ability of mutant sclerotome-de- rived cells to differentiate into prechondroblasts and chondroblasts, the expression of $\alpha 1(I I)$ collagen and scleraxis were examined. By $12.5 \mathrm{dpc}$, $\alpha 1$ (II) collagen transcripts mark the chondrogenic mesenchymal cells of the vertebrae and skull, prior to chondrocyte differentiation (Cheah et al. 1991). Examination of the vertebral column of 12.5 -dpc mutants reveals a significant reduction in the number of cells expressing $\alpha 1$ (II) collagen, particularly in the more anterior vertebrae (Fig. 6I,J; data not shown). In transverse sections through cervical and upper thoracic mutant vertebrae, $\alpha 1$ (II) collagen transcripts were detected in irregular dumbbell-like conden- 
sations of prechondrogenic cells surrounding the notochord (Fig. 6K,L). $\alpha 1$ (II) collagen is also expressed in the cranial mesenchyme destined to form the chondrocranium, the hyoid, and the laryngeal cartilages (Cheah et al. 1991). A marked reduction of $\alpha 1$ (II) collagen hybridization was observed in the region of the basisphenoid, whereas the malformed basioccipital region and Meckel's cartilage expression was normal in 12.5-dpc mutants (Fig. 6I,J; data not shown). scleraxis, which encodes a bHLH protein, is expressed in the lateral and then ventromedial sclerotome, the mesenchymal cells of the body wall, and the limb buds at $9.5 \mathrm{dpc}$. Subsequently, scleraxis RNA becomes restricted to the chondroblast precursors of the axial and appendicular skeleton and the cranial mesenchyme prior to terminal chondrogenesis (Cserjes et al. 1995). In 10.5- and 12.5-dpc mfh1-/- mutants, the level of scleraxis RNA within the limbs was not significantly altered (data not shown). However, scleraxis expression was reduced markedly in the vertebrae, nasal region, and lower jaw region of 12.5 -dpc mutant embryos (Fig. 6M-P). These findings suggest that $m f h 1$ is not absolutely required for the differentiation of condensing mesenchyme into chondroblasts but affects the number of more differentiated cells produced, because some scleraxis expression is seen (e.g., Fig. 6M-P).

The overall conclusion from these studies is that the reduction in level of expression of several mesodermal and sclerotomal markers in $m f h 1^{\text {tm } 1}$ mutants (e.g., twist, $\alpha 1$ (II) collagen, and scleraxis) reflects a reduction in the number of sclerotome-derived cells, rather than defects in their lineage and differentiation.

\section{Reduction of cell proliferation within the mfh1 -/- sclerotome}

No significant difference was observed in the level of

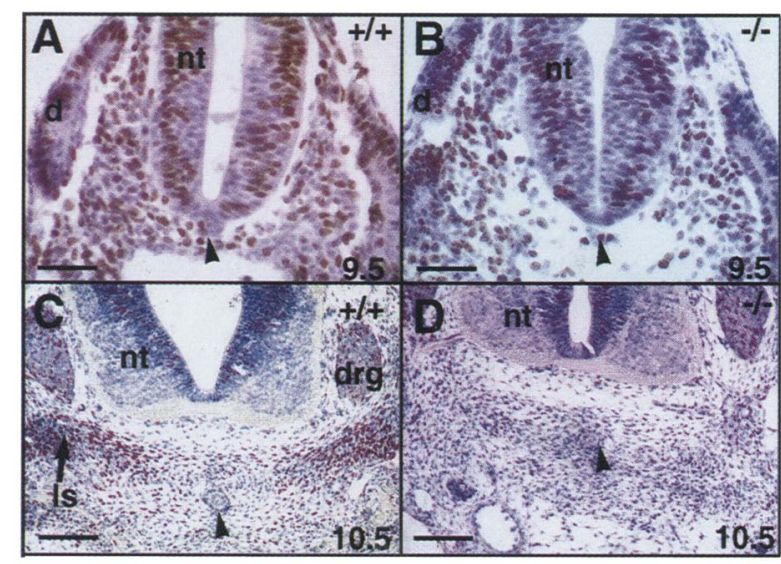

Figure 7. Reduced cell proliferation in the sclerotome of $m f h 1$ mutant embryos. Proliferative activity in the sclerotome of 9.5dpc wild-type and mutants embryos $(A, B)$ was detected by BrdU immunohistochemistry. $(C, D)$ The sclerotome of 10.5 -dpc wildtype and $m f h 1-/-$ embryos. Note the very high level of BrdU labeling in the lateral sclerotome (ls) of wild type compared with mutant. Bars: $(A, B) 25 \mu \mathrm{m}_{;}(C, D) 60 \mu \mathrm{m}$. (d) dermomyotome; (drg) dorsal root ganglia; (nt) neural tube; (arrowhead) notochord.
Table 3. Cell proliferation in the sclerotome and neural tube/dorsal root ganglia

\begin{tabular}{rcccccc}
\hline & \multicolumn{2}{c}{$\begin{array}{c}\text { Percentage of sclerotome } \\
\text { cells labeled with } \\
\text { BrdU } \pm \text { S.E.M. }\end{array}$} & & \multicolumn{2}{c}{$\begin{array}{c}\text { Percentage of neural } \\
\text { tube/dorsal root } \\
\text { ganglia cells labeled } \\
\text { with BrdU } \pm \text { S.E.M. }\end{array}$} \\
\cline { 2 - 4 } \cline { 6 - 7 } Age & wild & mfh1 & inhibition & & wild & mh1 \\
(dpc) & type & $(-/-)$ & $(\%)$ & & type & $(-/-)$ \\
\hline 9.5 & $65 \pm 1$ & $52 \pm 1$ & 20 & & $51 \pm 1$ & $50 \pm 1$ \\
10.5 & $29 \pm 1$ & $15 \pm 1$ & 48 & & $48 \pm 1$ & $49 \pm 1$ \\
11.5 & $32 \pm 2$ & $14 \pm 1$ & 58 & & $30 \pm 2$ & $31 \pm 1$ \\
12.5 & $31 \pm 2$ & $13 \pm 2$ & 56 & & $25 \pm 1$ & $25 \pm 2$ \\
\hline
\end{tabular}

Embryos were labeled in vivo with BrdU for $1.5 \mathrm{hr}$ and sections stained by immunohistochemistry as described in Materials and Methods. As an internal control, nuclei from the neural tube at $9.5 \mathrm{dpc}$ and $10.5 \mathrm{dpc}$, and dorsal root ganglia at $11.5 \mathrm{dpc}$ and 12.5 $\mathrm{dpc}$ were scored. The fraction of BrdU-labeled cells was determined by dividing the number of positive nuclei (brown) by the total number of nuclei. Groups of three to four consecutive sections from the same embryo were used. For each stage examined, wild-type data were pooled from 9 sections from four embryos while the mutant data were pooled from 12 sections from four embryos. Data are expressed as the mean \pm S.E.M.

programmed cell death in the sclerotome and cephalic mesenchyme of $m f h 1^{t m 1}$ mutant or wild-type embryos, as determined by TUNEL labeling (data not shown). We therefore examined the effect of the $m f h 1$ deletion on the proliferation of sclerotome cells, as judged by bromodeoxyuridine (BrdU) incorporation. A striking difference was observed in the BrdU labeling of mutant sclerotomederived regions from $9.5 \mathrm{dpc}$ to $12.5 \mathrm{dpc}$, compared with wild-type littermates (Fig. 7). Quantitation of these results is presented in Table 3 . These data show a $20 \%$ to $58 \%$ reduction in the proliferative activity of the sclerotome-derived cells. A similar reduction was not seen in neural tissue.

In conclusion, the reduction of prechondrocyte markers observed in the $m f h 1^{t m 1}$ mutants may be attributed, at least in large part, to the reduced proliferation of cells derived from the sclerotome and cephalic mesenchyme, rather than to an increase in programmed cell death.

\section{$\mathrm{mfh} 1$-/-somite micromass cultures fail to generate chondrogenic nodules}

To test whether the abnormal proliferation of $m f h 1-1-$ sclerotome cells in vivo could be reproduced or rescued in vitro, micromass cultures were prepared from somites of 10.5-dpc $m f h 1$ mutants and wild-type embryos. They were grown for 6 days under controlled conditions (with or without growth factors), and then stained with alcian blue to detect chondrogenic nodules. As shown in Figure 8, A and C, normal and mutant cells attached equally well to the substratum. However, mutant cultures failed to increase in density after $24 \mathrm{hr}$. By $48 \mathrm{hr}$, a large num- 


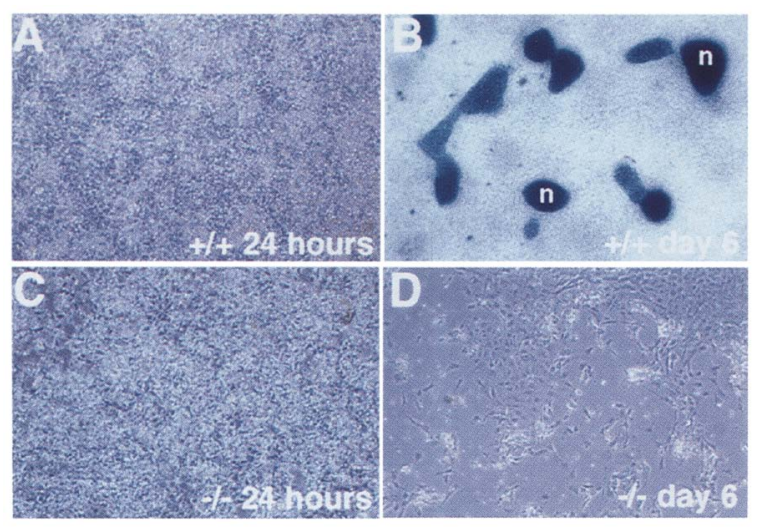

Figure 8. Somite micromass cultures from wild-type and $m f h 1$ -/- embryos. $(A, C)$ Wild type and $m f h 1-/$ - cultures after $24 \mathrm{hr}$ in $2 \%$ FBS, showing a uniform layer of fibroblast-like cells. $|B, D|$ After 6 days, cultures were fixed and stained with alcian blue to detect chondrogenic nodules $(\mathrm{n})$. (B) In wild-type cultures, alcian blue-stained nodules $(\mathbf{n})$ were observed. $(D)$ No alcian bluestained nodules were observed in $m f h 1-/$ - cultures and most cells had detached.

ber of mutant cells began to dissociate from the dish, suggesting a loss of cell adhesiveness, a block in cell proliferation, or increase in cell death. After 6 days, -25 chondrogenic nodules were detected in wild-type and heterozygous cultures (Fig. 8B). In contrast, no chondrogenic nodules were observed in the small number of cells remaining in $m f h 1-/$ - cultures (Fig. 8D).

To see whether the mfh1 mutant cells in vitro can be rescued by the addition of exogenous transforming growth factor- $\beta$ (TGF- $\beta$ ) and fibroblast growth factor (FGF), two growth factors that have been shown to stimulate chondrogenesis in somite micromass cultures (Frenz et al. 1994; Grass et al. 1996), the cultures were treated with basic FGF (bFGF) alone or with bFGF and TGF $\beta 1$ from the time of plating. Both wild-type and heterozygous cultures generated equal amounts of chondrogenic nodules, as detected by alcian blue staining. However, the $m f h 1-/$ - cultures were not rescued by the addition of these growth factors. We conclude that the inability to generate chondrogenic nodules in mutant somites cultures, even in the presence of several growth factors, is consistent with defects of sclerotomal cell proliferation observed in vivo.

\section{Discussion \\ Deletion of the $\mathrm{mfh} 1$ gene results in a lethal phenotype}

We have shown here that absence of $m f h 1$ leads to pre- or perinatal lethality. The few pups that survive to birth show loss or malformation of elements of the vertebral column, ribs, and skull bones. The more severely affected embryos show a specific decrease in the proliferation of sclerotome-derived cells in vivo and their somite cells fail to grow and differentiate normally into cartilage in culture. These results provide the first evidence that a member of the winged helix/forkhead gene family is required for the normal growth and patterning of paraxial mesodermal derivatives during mouse embryogenesis.

Embryos homozygous for the $m f h 1^{t m 1}$ allele begin to die $-12.5-13.5 \mathrm{dpc}$, probably because of a failure in the circulatory system, as judged by the presence of extravascular blood pools. $m f h 1$ is normally expressed in endothelial cells of blood vessels, suggesting a role in their growth and differentiation. Chick-quail fate mapping studies have revealed that paraxial mesoderm (i.e., somites) gives rise to the endothelium of the intersegmental blood vessels (Noden 1989; Couly et al. 1995). Although major abnormalities were not observed in the heart, defects were observed in the vascular system of the more severely affected homozygous mutants (Fig. 3). These observations are consistent with a role for $m f h 1$ in the generation or proliferation of paraxial mesoderm giving rise to intersegmental vessels. In addition there may be subtle defects in vessel integrity, permeability, or other properties that are the cause of death later in embryogenesis. Further studies are needed to solve this problem.

$\mathrm{mfh} 1$ is not required for the formation of epithelial somites and their early patterning and differentiation

Our in situ hybridization studies and those of others (Miura et al. 1993; Kaestner et al. 1996a) show that mfh1 is expressed in the presomitic mesoderm, the epithelial somites, transiently in the dermomyotome and lateral myotome (Fig. 1), and then in sclerotome-derived cells. Our analysis shows that the initial formation of epithelial somites and their dorsoventral, mediolateral, and anterioposterior patterning appear to be normal in homozygous mutants, as judged by the expression of a variety of mesoderm specific markers (Fig. 6). This result suggests either that $m f h 1$ has no function during the early stages of somitogenesis or, more likely, that the absence of a functional gene product is compensated for in vivo by other members of the winged-helix gene family, for example $m f 1(f k h 1), m f 2$, and $m f 3(f k h 5)$, which are expressed in presomitic mesoderm and/or paraxial mesoderm and somite-derived populations (Sasaki and Hogan 1993; Costa 1994; Kaestner et al. 1996b; Kaufmann and Knochel 1996; Labosky et al. 1996). This possibility is currently being tested by generating embryos homozygous for mutations in some of these genes and by making double mutants. Compensation by other winged helix/ forkhead family members is also the likely reason why defects are not seen in the appendicular skeleton of $m f h 1$ mutants.

$\mathrm{mfhl}$ affects the proliferation of sclerotome-derived cells in vivo and in vitro

A striking finding from our studies is that $m f h 1$ affects the proliferation of sclerotome-derived cells, as judged by the reduced incorporation of BrdU into homozygous mutant cells in vivo (Fig. 7; Table 3). This defect is seen as 
early as $9.5 \mathrm{dpc}$ in sclerotome-derived cells, and appears to be specific for these cells that normally express $m f h 1$, because neural tube or dorsal root ganglia proliferation remains unchanged (Table 3). One possible explanation for these results is that $m f h 1$ controls the expression of a cell-autonomous receptor for a growth factor that stimulates progression through the cell cycle. Alternatively, or in addition, MFHl may be part of a downstream signaling pathway from a growth factor receptor (Soriano 1994). A likely candidate would be a receptor for a bone morphogenetic protein (BMP), because these cytokines are known to promote chondrogenesis in vitro, and at least some members of the BMP superfamily, such as BMP5 and GDF5 (Kingsley et al. 1994), are required for the formation of specific cartilage elements in vivo. Moreover, a winged helix/forkhead protein, FAST, recently has been identified in a complex with a xenopus mothers-against-dpp (XMAD) protein that has been linked to activin signaling in Xenopus embryos (Chen et al. 1996). The expression of genes for BMPs or BMP receptors currently is being examined in the sclerotome of $m f h 1$ mutants. Another possibility is that $m f h 1$ regulates the expression of an autocrine growth factor produced by the sclerotome cells and required for their proliferation. However, preliminary studies failed to show any significant difference between the expression of $i h h$, $b m p 2$, and $b m p 7$ in wild-type and homozygous mutant embryos (data not shown).

The reduced proliferation capacity of $m f h 1$ homozygous mutant cells in vivo also appears to be a characteristic of $m f h 1$ mutant cells in micromass cultures in vitro (Fig. 8). Mutant cells attach to the substratum normally for up to $24 \mathrm{hr}$, suggesting that cell-substrate and cellcell adhesion are not grossly defective. However, the density of the cultures does not increase, and by $48 \mathrm{hr}$ the cells begin to detach in large numbers, and no cartilage nodules form after 6 days. Recent somite micromass culture experiments have shown that the first $48 \mathrm{hr}$ is the period of maximal cell proliferation (George-Weinstein et al. 1994). The abnormal phenotype of $m f h 1 \mathrm{mu}-$ tant cells in vitro cannot be rescued by the addition of exogenous TGF- $\beta$ and FGF, two growth factors that stimulate chondrogenesis in somite micromass cultures (Frenz et al. 1994; Grass et al. 1996). These findings, although consistent with a defect in cell proliferation, do not rule out an independent or related defect in the ability of mutant cells to aggregate, to survive in culture, or to differentiate along the chondrogenic pathway. However, the fact that the mutant phenotype can be revealed in culture opens up possibilities for exploring MFH1 function at the cellular and biochemical level.

\section{Does mfhl affect sclerotomal-derived cell differentiation as well as proliferation?}

We have shown here that $m f h 1$ affects the proliferation of sclerotome-derived cells. Studies on other winged helix/forkhead genes have provided evidence for a role in both cell proliferation, differentiation, and cell fate decisions (Miller et al. 1993; Xuan et al. 1995; for review, see
Kaufmann and Knochel 1996). For example, disruption of the brain factor 1 (bf1) gene results in a decrease in the rate of proliferation of undifferentiated neurectodermal cells in the ventral telencephalon (Xuan et al. 1995; Kaufmann and Knochel 1996). In addition, a marker of early postmitotic neurons was expressed prematurely in the dorsal telencephalon of $b f 1$ mutants, suggesting that the precursor cells exiting from the cell cycle were differentiating earlier than normal (Xuan et al. 1995). Another example is the phenotype of embryos with a disruption of brain factor 2 (bf2). This results in reduced differentiation of the condensing mesenchyme of the kidney into tubular epithelium, as well as decreased growth and branching of the ureter and collecting system (Hatini et al. 1996).

Therefore, we have considered the possibility that mfh1 mutant cells are defective in their ability to differentiate along the pathway from multipotent sclerotomal cells to mature chondroblasts making up different regions of the vertebrae (vertebral body, intervertebral disc, neural arch, rib, etc). Unfortunately, this analysis is hampered by the absence of molecular markers characterizing specific populations of precursor cells, for example, migrating sclerotome cells, condensing sclerotome cells, prechondroblasts, and chondroblasts. Our experiments to date suggest that $m f h 1$ mutant cells are able to differentiate into migrating and condensing sclerotome cells that express pax 1 and pax 9 . They can also give rise to some cells that express $\alpha 1$ (II) collagen and scleraxis. However, the overall level of expression of these and other markers (e.g., $m f 1$ and $m t w i s t$ ) is reduced in sclerotome-derived regions of homozygous mutant embryos (Fig. 6), in a manner that suggests that the number and density of expressing cells is reduced. The dumbbell pattern of $\alpha 1$ (II) collagen and pax1 expression (Fig. 6) and the formation of two small centers of ossification in the vertebral bodies of the posterior vertebrae is also consistent with a reduced migration of sclerotome-derived cells and/or a delay in endochondral ossification in mutants.

A schematic model summarizing our ideas about the functional role of $m f h 1$ is presented in Figure 9. During the normal development of the vertebra, cells of the sclerotome lineage differentiate along a pathway that is still poorly understood but that includes epithelial and early sclerotome, migrating sclerotome, and condensing sclerotome. The condensed sclerotome then differentiates into chondroblasts and chondrocytes, with some relatively undifferentiated chondroblast precursors remaining in the perichondral layer. At each stage, the population of precursor cells needs to undergo clonal expansion to generate a pool of progenitor cells in which the next differentiation program can be initiated. We propose that an important role for $m f h 1$ is to regulate or facilitate the clonal expansion that takes place in sclerotome-derived lineages as they migrate ventrally, laterally, and medially, and then condense. We cannot at this time eliminate some role for $\mathrm{MFHl}$ in regulating differentiation steps, or processes such as cell adhesion and migration. However, it is also possible that some abnor- 


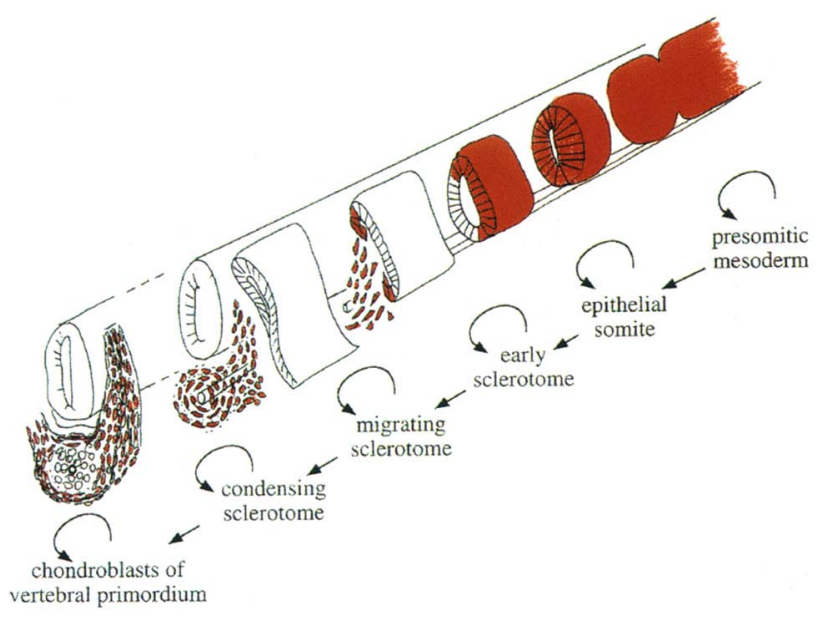

Figure 9. Schematic representation of $m f h 1$ expression during the growth and differentiation of the sclerotome. The sclerotome lineage arises from multipotent stem cells in the epithelial somite, as a result of inductive signals from the notochord. Cells then migrate medially, ventrally, and laterally. Those that condense around the notochord give rise to the cartilage primordium of the vertebral body and centrum, whereas the medial and lateral condensations give rise to the neural arches and pedicles. Sclerotomal cells also give rise to intervertebral discs and connective tissue around the spinal ganglia and nerves. Vertebral formation involves an ordered progression of differentiated progenitor cell populations, leading finally to the appearance of postmitotic chondrocytes and osteocytes. Each population undergoes proliferative expansion (curved arrows), presumably in response to cytokines and growth factors, to generate a pool of precursor cells in which the next differentiation step can occur. We propose that $m h f 1$ (expression shown in red) plays a role in regulating clonal expansion, and possibly also progression along the differentiation pathway. A similar role for $m f h 1$, in combination with related genes, may also occur in the formation of the appendicular skeleton.

malities in these processes in vivo and in vitro may be a secondary consequence of local lower cell densities or smaller cell population numbers. Further experiments will be needed to test this hypothesis.

\section{Materials and methods}

\section{Construction of targeting vector}

Six $m f h 1$ genomic DNA clones were isolated from a $129 / \mathrm{SvJ}$ mouse genomic library (Stratagene) using an mfl cDNA probe including sequences encoding the winged helix domain. Two overlapping 1-clones (Mfh- $\mathrm{lb}$ and Mfhl-11) were shown by restriction mapping, Southern blot analysis, and sequencing to correspond to the $m f h 1$ locus shown in Figure 2. The remaining clones mapped within this $m f h 1$ locus. A targeting vector was constructed using a 1.1-kb 5 ' homology region (XhoI fragment) and a 3.0-kb 3' homology arms (EcoRI fragment). The entire coding region was replaced with a PGKneor cassette from the pPNT vector (Tybulewicz et al. 1991; gift from J. Rossant, Mt. Sinai Hospital, Toronto, Canada), resulting in the deletion of the mfh1 coding exon including untranslated regions. For negative selection a phosphoglycerokinase thymidine kinase (PGK TK) cassette was attached to the $3^{\prime}$ end of the targeting vector.
The targeted allele is designated $m f h 1^{\text {tm } 1 b l h}$ according to the guidelines of the International Committee on Standardized Genetic Nomenclature for Mice (The Jackson Laboratory, Bar Harbor, ME).

Generation of recombinant ES cell clones and mouse chimeras

Approximately $2-7 \times 10^{7}$ ES cells of line TL1 (derived by Patricia A. Labosky, University of Pennsylvania Medical School, Philadelphia, from 129/ SvEvTaconic Brouser blastocysts) at passage 15 were electroporated with $100 \mu \mathrm{g}$ of NotI-digested replacement vector DNA in a total of $800 \mu$ l of PBS using a single pulse from a gene pulser (Bio-Rad) at $800 \mathrm{~V}$ and $3 \mu \mathrm{F}$. The cells were then plated on irradiated neo ${ }^{r}$ primary mouse embryo fibroblasts and selected as described by Winnier et al. (1995). Of the 105 double resistant colonies screened, three were found to have the correctly targeted allele, giving an overall frequency of one in 35. Two clones, Dl and 5E, were injected into host (C57BL/6) blastocysts as described (Hogan et al. 1994), and both gave germ-line transmission of the mutant allele. Chimeras were mated with Black Swiss females (Taconic), and agouti offspring analyzed by Southern blot hybridization for the presence of the targeted allele $\left(m f h 1^{t m 1}\right)$. Intercrossing of heterozygotes yielded no surviving homozygous mutants, and further analyses were performed on a mixed $(129 \times$ Black Swiss $)$ background. Both lines exhibited the same phenotype.

\section{Genomic DNA analysis}

For the extraction of genomic DNA, ES cells, tail biopsies, and yolk sacs were lysed in $[100 \mathrm{~mm}$ Tris- $\mathrm{HCl}$ at $\mathrm{pH} 7.5,50 \mathrm{~mm}$ EDTA, $0.5 \%$ SDS, $0.1 \mathrm{mg} / \mathrm{ml}$ of proteinase $\mathrm{K}$ [Sigma)] and digested overnight at $56^{\circ} \mathrm{C}$. DNA was prepared by phenol-chloroform extractions and ethanol precipitation and resuspended in TE (10 mM Tris-HCl at pH 8.0,0.1 mM EDTA). Southern blots were performed as described (Church and Gilbert 1984). Ten micrograms of genomic DNA was digested with SpeI restriction endonuclease. Southern blots were hybridized with the $5^{\prime} 1.1$ $\mathrm{kb}$ HindIII-XhoI probe. A $12.5-\mathrm{kb}$ fragment corresponding to the wild-type allele and a 4.5 -kb fragment corresponding to the targeted allele were identified on Southern blots (Fig. 2C).

\section{Skeletal preparation}

Skeletal preparations were performed as described by Kimmel and Tramwell (1981). In brief, neonatal mice and embryos were placed in water overnight and eviscerated. Skeletons were fixed in $95 \%$ ethanol for 3 days followed by alcian blue staining [15 $\mathrm{mg}$ of alcian blue $8 \mathrm{GX}$ (Sigma), $80 \mathrm{ml}$ of $95 \%$ ethanol, $20 \mathrm{ml}$ of glacial acetic acid] for $24 \mathrm{hr}$. Skeletons were then rinsed in $95 \%$ ethanol overnight and cleared in $1 \%$ potassium hydroxide $(\mathrm{KOH})$ for $6 \mathrm{hr}$. Counterstaining for bone was performed using alizarin red (Sigma, $50 \mathrm{mg} /$ liter of $2 \% \mathrm{KOH}$ ) for $2 \mathrm{hr}$. Skeletons were cleared in $2 \% \mathrm{KOH}$ and stored in $100 \%$ glycerol.

\section{In situ hybridizations}

Whole-mount in situ hybridization was performed as described (Winnier et al. 1995). The following murine cDNAs were used as templates for synthesizing antisense or sense strand digoxygenin labeled riboprobes and $\left[\alpha-{ }^{35} \mathrm{~S}\right] \mathrm{UTP}$ RNA probes: $3.0-\mathrm{kb}$ mfh1 cDNA (3BB); 900-bp mf1 (C52); 850-bp mf2, mf3 (e4.3) (Sasaki and Hogan 1993); 650 bp mfkh6 (kindly provided by Klaus Kaestner, University of Pennsylvania, Philadelphia); 1.2kb bmp2 (Blessing et al. 1993); 800-bp bmp7 (kindly provided by 
Dr. Karen Lyons, University of California, Los Angeles); 470-bp $f g f R 1$ (kindly provided by Dr. Jill McMahon, Harvard University, Cambridge, MA); 1.8-kb myoD; 1.2-kb myogenin; 400-bp notch1 (kindly provided by Dr. Thomas Gridley, The Jackson Lab, Bar Harbor, ME); 1.0-kb paraxis (kindly provided by Dr. Thomas Quertermous, Vanderbilt University Medical School, Nashville, TN); 1.3-kb twist (kindly provided by Dr. Richard Behringer, MD Anderson Cancer Center, Houston, TX); 900-bp scleraxis (kindly provided by Dr. Eric Olson, UT Southwestern Medical Center, Dallas, TX); 620-bp fgf4 (kindly provided by Dr. Lee Niswander, Sloan Kettering Institute, New York, NY); 313 bp pax1 (pmprd) and 660-bp pax1 (3' UTR) (kindly provided by Dr. Chen-Ming Fan, Carnegie Institute, Baltimore, MD); 291-bp pax 9 (kindly provided by Dr. Annette Neusbauer, University of California, San Fransisco); 405-bp $\alpha 1$ (II) collagen and 515-bp mox1 (provided by Dr. C.V.E. Wright, Vanderbilt University Medical School, Nashville, TN). In situ hybridization with $\left[\alpha{ }^{-35}\right.$ S UTP RNA probes was performed using a protocol described previously by Zhao et al. (1993).

\section{Whole-mount immunostaining}

The whole-mount immunostaining protocol described below was kindly provided by Dr. Scott Baldwin (Wistar Institute, Philadelphia, PA). Embryos were dissected in calcium/magnesium free phosphate-buffered saline (PBS) and $0.1 \%$ BSA, fixed overnight at $4{ }^{\circ} \mathrm{C}$ in Dent fixative ( $80 \%$ methanol, $20 \% \mathrm{DMSO}$ ), washed three times in $100 \%$ methanol, and then stored at $-20^{\circ} \mathrm{C}$ until use.

Embryos were bleached in $6 \%$ hydrogen peroxide in methanol for $1 \mathrm{hr}$ and then rehydrated in a reverse series of methanol dilutions $(75 \%, 50 \%, 25 \%)$ and blocked in antibody dilution buffer $4 \%$ BSA, $0.01 \% \mathrm{NaN}_{3}, 10 \%$ goat serum in PBS) twice at $4^{\circ} \mathrm{C}$ for $1 \mathrm{hr}$ to block nonspecific sites. The embryos were incubated at $4^{\circ} \mathrm{C}$ overnight in primary antibody $(5-20 \mu \mathrm{g} / \mathrm{ml})$ in dilution buffer, followed by three quick washes with TBST (Tris-buffered saline with $0.1 \%$ Tween 20 ) containing $2 \mathrm{~mm}$ levamisole, then $5-71-\mathrm{hr}$ washes at $4^{\circ} \mathrm{C}$. The embryos were then incubated in 1:200 dilution of goat anti-rat alkaline phosphatase conjugate (Jackson ImmunoResearch Laboratories) in $10 \%$ goat serum, $4 \%$ BSA in PBS with $0.01 \% \mathrm{NaN}_{3}$ overnight at $4^{\circ} \mathrm{C}$. No secondary antibody was added for the negative control. Following the incubation, embryos were given 5-7 1-hr washes with TBST containing $2 \mathrm{~mm}$ levamisole, followed by two 15 min washes in NTMT ( $100 \mathrm{~mm} \mathrm{NaCl}, 100 \mathrm{~mm}$ Tris at pH 9.5, 50 $\mathrm{mM} \mathrm{MgCl} 2,0.1 \%$ Tween 20 ) containing $2 \mathrm{~mm}$ levamisole. Coloring reactions were performed in coloring solution $(4.5 \mu 1 / \mathrm{ml}$ of NBT, $3.5 \mu \mathrm{l} / \mathrm{ml}$ and $2 \mathrm{~mm}$ levamisolel in the dark without rocking. Color development was continued for 8-10 min. The reaction was stopped by three washes of PBT, and embryos were stored in the dark at $4^{\circ} \mathrm{C}$.

\section{Cell proliferation and apoptosis}

$\mathrm{BrdU}$ (Sigma) and fluorodeoxyuride (FUdr) (Sigma) were injected intraperitonally into pregnant mice, $1.5 \mathrm{hr}$ before sacrifice. Embryos were fixed in $4 \%$ paraformaldehyde for $2-4 \mathrm{hr}$ and embedded in paraffin. Sections $(8 \mathrm{~mm})$ were dewaxed and stained as described (Bellusci et al. 1996). To determine the rate of cell proliferation in the sclerotome, photomicrographs were taken at $20 \times$ magnification and cells surrounding the notochord and lateral regions were counted. Cells in four adjacent sections from the thoracic region, spanning $-160 \mu \mathrm{m}$ anterioposteriorly, from four independent wild-type and $m f h 1$ mutants were scored as labeled or unlabeled. All the cells of the neural tube or dorsal root ganglia were scored as labeled or unlabeled as an internal control. The overall percentage of labeled nuclei was determined and analyzed by Student's t-test using the SAS 6.10 program. Results were determined to be significant if $P<0.05$.

Cell death analysis was performed using the Apoptag Plus detection kit (Oncor) essentially following the manufacturer's instructions with minor modifications. Sections were dewaxed and rehydrated through a series of ethanols $100 \%, 95 \%, 75 \%$, $50 \%$, and $25 \% \mid$ and rinsed in PBS. Proteinase $\mathrm{K}$ digestion was optimized to $10 \mathrm{~min}$. Sections were incubated with terminal deoxynucleotide transferase (TdT) and digoxygenin-dUTP for 1 hr before quenching in $3 \%$ hydrogen peroxide for $10 \mathrm{~min}$ at room temperature. The incorporated digoxygenin-dUTP was detected using an anti-digoxygenin-peroxidase coupled antibody with fast DAB tablets (Sigma). Sections were counterstained with either methylene blue or hematoxylin.

\section{Somite micromass cultures}

For micromass cultures, somites (11-36), which were isolated from individual wild-type, heterozygous, and $m f h 1$ null mutant 10.5-dpc embryos, were dissected in ice-cold PBS, and treated with $0.5 \mathrm{mg} / \mathrm{ml}$ of dispase for $10 \mathrm{~min}$. Isolated somites were digested with $0.1 \%$ collagenase and $0.1 \%$ trypsin for $20 \mathrm{~min}$ at $37^{\circ} \mathrm{C}$ with occasional shaking. The somitic cells were dissociated by pipetting and resuspended in DMEM, $2 \%$ fetal bovine serum (FBS) in $20 \mu \mathrm{l}$ drops at $2 \times 10^{7}$ cells $/ \mathrm{ml}$ in six-well dishes (Nunc). Some cultures were treated with either $10 \mathrm{ng} / \mathrm{ml}$ of bFGF alone or with $10 \mathrm{ng} / \mathrm{ml}$ of bFGF and $10 \mathrm{ng} / \mathrm{ml}$ of TGF- $\beta 1$. Cultures were grown at $37^{\circ} \mathrm{C}$ in a humidified incubator for 6 days and fixed for $10 \mathrm{~min}$ in $4 \%$ buffered formalin. To stain for chondrogenic nodules, cultures were incubated at $37^{\circ} \mathrm{C}$ overnight in $1 \mathrm{mg} / \mathrm{ml}$ of alcian blue in $1 \mathrm{~N} \mathrm{HCl}$. The presence of alcian blue staining was determined by visualization using light microscopy.

\section{Acknowledgments}

We thank Drs. Hiroshi Sasaki, Manfred Blessing, and Patricia Labosky for excellent advice and technical assistance with gene targeting; Lorene Batts for technical support; Dr. Rudy Balling for insightful advice; and Drs. Achim Gossler and Chris Wright for critical and helpful comments on the manuscript. B.L.M.H. is an Investigator of the Howard Hughes Medical Institute.

The publication costs of this article were defrayed in part by payment of page charges. This article must therefore be hereby marked "advertisement" in accordance with 18 USC section 1734 solely to indicate this fact.

\section{References}

Bagnall, K.M. 1992. The migration and distribution of somite cells after labelling with the carbocyanine dye, DiI: The relationship of this distribution to segmentation in the vertebrate body. Anat. Embryol. 185: 317-324.

Baldwin, H.S., H.M. Shen, H.-C. Yan, H.M. DeLisser, A. Chung, C. Mickanin, T. Trask, N.E. Kirschbaum, P.J. Newman, S.M. Albelda, and C.A. Buck. 1994. Platelet endothelial cell adhesion molecule 1 (PECAM-1/CD31): Alternatively spliced, functionally distinct isoforms expressed during mammalian cardiovascular development. Development 120: 2539-2553.

Balling, R., C.F. Las, S. Dietrich, J. Wallin, and P. Gruss. 1992. Development of the skeletal system. Postimplantation development in the mouse. CIBA Found. Symp. 165: 132-143.

Beddington, R.S.P. 1981. An autoradiographic analysis of the potency of embryonic ectoderm in the 8 th day postimplan- 
tation mouse embryo. I. Embryol. Exp. Morphol. 64: 87-109. -1982. An autotradiographic analysis of the tissue potency in different regions of the embryonic ectoderm during gastrulation in the mouse. I. Embryol. Exp. Morphol. 69: $265-285$.

Bellusci, S., R. Henderson, G.E. Winnier, T. Oikawa, and B.L.M. Hogan. 1996. Evidence from normal expression and targeted misexpression that Bone morphogenetic Protein-4 (Bmp-4) plays a role in mouse embryonic lung morphogenesis. Development 122: 1693-1702.

Blessing, M., L.B. Nanny, L.E. King, C.M. Jones, and B.L.M. Hogan. 1993. Transgenic mice as a model to study the role of TGF- $\beta$-related molecules in hair follicles. Genes \& Dev. 7: 204-215.

Bober, E., B. Brand-Saberi, C. Ebernsperger, J. Wilting, R. Balling, R.B. Paterson, H.-H. Arnold, and B. Christ. 1994. Initial steps of myogenesis in somites are independent of influence from axial structures. Development 120: 3073-3082.

Buffinger, N. and F.E. Stockdale. 1994. Myogenic specification in somites: Induction by axial structures. Development 120: $1443-1452$.

Burgess, R., P. Cserjeshi, K.L. Ligon, and E.N. Olson. 1995. Paraxis: A basic helix-loop-helix protein expressed in paraxial mesoderm and developing somites. Dev. Biol. 168: 296-306.

Candia, A.F., J. Hu, J. Crosby, P.A. Lalley, D. Noden, J.H. Nadeau, and C.V.E. Wright. 1992. Mox-1 and Mox-2 define a novel homeobox gene subfamily and are differentially expressed during early mesodermal patterning in mouse embryos. Development 116: 1123-1136.

Cheah, K.S.E., E.T. Lau, P.K.C. Au, and P.P.L. Tam. 1991. Expression of the mouse $\alpha 1$ (II) collagen gene is not restricted to cartilage during development. Development 111: 945-953.

Chen, X., M.J. Rubock, and M. Whitman. 1996. A transcriptional partner for MAD proteins in TGF- $\beta$ signaling. Nature 383: 691-696.

Christ, B. and C.P. Ordahl. 1995. Early stages of chick somite development. Anat. Embryol. 191: 381-396.

Church, G.M. and W. Gilbert. 1984. Genomic sequencing. Proc. Natl. Acad. Sci. 81: 1991-1995.

Costa, R.H. 1994. Hepatocyte nuclear factor $3 /$ forkhead protein family: Mammalian transcription factors that possess divergent cellular expression patterns and binding specificities. In Liver gene expression (ed. F. Tronche and M. Yaniv), pp. 183-205. R.G. Landes, Austin, Texas.

Couly, G., P. Coltey, A. Eichmann, and N.M. LeDouarin. 1995. The angiogenic potentials of the cephalic mesoderm and the origin of brain and head blood vessels. Mech. Dev. 53:97112.

Cserjes, P., D. Brown, K.L. Ligon, G.E. Lyons, N.G. Copeland, D.J. Gilbert, N.A. Jenkins, and E.N. Olson. 1995. Scleraxis: A basic helix-loop-helix protein that prefigures skeletal formation during mouse embyrogenesis. Development 121: 1099-1110.

Deutsch, U., G.R. Dresseler, and P. Gruss. 1988. Pax-1, a member of a paired box homologous murine gene family, is expressed in segmented stuctures during development. Cell 53: 617-625.

Dietrich, S. and P. Gruss. 1995. Undulated phenotypes suggest a role of Pax-1 for the development of vertebral and extravertebral structures. Dev. Biol. 167: 529-548.

Dietrich, S., F.R. Schubert, and P. Gruss. 1993. Altered Pax gene expression in murine notochord mutants: The notochord is required to initiate and maintain ventral identity in the somite. Mech. Dev. 44: 189-207.

Fan, C.-M. and M. Tessier-Lavigne. 1994. Patterning of mam- malian somites by surface ectoderm and notochord: Evidence for sclerotome induction by a Hedgehog homolog. Cell 79: 1175-1186.

Fan, C.-M., J.A. Porter, C. Chiang, D.T. Chang, P.A. Beechy, and M. Tessier-Lavigne. 1995. Long-range sclerotome induction by Sonic hedgehog: Direct role of the amino-terminal cleavage product and modulation by the cyclic AMP signaling pathway. Cell 81: 457-465.

Frenz, D.A., W. Liu, J.D. Williams, V. Hatcher, V. GalinovicSchwartz, K.C. Flanders, and T.R. Van De Water. 1994. Induction of chondrogenesis: Requirement for synergistic interaction of basic fibroblast growth factor and transforming growth factor-beta. Development 120: 415-424.

George-Weinstein, M., J.V. Gerhart, G.J. Foti, and J.W. Lash. 1994. Maturation of myogenic and chondrogenic cells in the presomitic mesoderm of the chick embryo. Exp. Cell Res. 211: 263-274.

Grass, S., H.-H. Arnold, and T. Braun. 1996. Alternations in somite patterning of Myf5-deficient mice: A possible role for FGF-4 and FGF-6. Development 122: 141-150.

Hatini, V., S.O. Huh, D. Herzlinger, V.C. Soares, and E. Lai. 1996. Essential role of stromal mesenchyme in kidney morphogenesis revealed by targeted disruption of winged Helix transcription factor BF-2. Genes \& Dev. 10: 1467-1478.

Hogan, B.L.M., R. Beddington, F. Costantini, and E. Lucy. 1994. Manipulating the mouse embryo: A laboratory manual, 2nd. ed. Cold Spring Harbor Laboratory Press, Cold Spring Harbor, NY.

Johnson, R. 1986. The genetics of the skeleton. Clarendon Press, Oxford, UK

Kaestner, K.H., K.-H. Lee, J. Schlondorff, H. Hiemisch, A.P. Monaghan, and G. Schulz. 1993. Six members of the mouse forkhead gene family are developmentally regulated. Proc. Natl. Acad. Sci. 90: 7628-7631.

Kaestner, K.H., S.C. Bleckmann, A.P. Monaghan, J. Schlondorff, A. Mincheva, P. Lichter, and G. Schutz. 1996a. Clustered arrangement of winged helix genes fkh-6 and MFH-1: Possible implications for mesoderm development. Development 122: 1751-1758.

Kaestner, K.H., G. Schutz, and A.P. Monaghan. 1996b. Expression of the winged helix genes fkh- 4 and fkh-5 defines domains in the central nervous system. Mech. Dev. 55: 221230.

Kaufmann, E. and W. Knochel. 1996. Five years on the wings of fork head. Mech. Dev. 57: 3-20.

Kimmel, C.A. and C. Tramwell. 1981. A rapid procedure for routine double staining of cartilage and bone in fetal and adult animals. Stain Technol. 56: 271-272.

Kingsley, D.M. 1994. The TGF- $\beta$ superfamily: New members, new receptors, and new genetic tests of function in different organisms. Genes \& Dev. 8: 133-146.

Koseki, H., J. Wallin, J. Wilting, Y. Mizutani, A. Kispert, C. Ebensperger, B.G. Herrman, B. Christ, and R. Balling. 1993. A role for Pax-1 as a mediator of notochordal signals during the dorsoventral specification of vertebrae. Development 119: 649-660.

Labosky, P.A., G.E. Winnier, H. Sasaki, M. Blessing, and B.L.M. Hogan. 1996. The chromosomal mapping of four genes encoding winged helix proteins expressed early in mouse development. Genomics 34: 241-245.

Miller, L.M., M.E. Gallegos, B.A. Morisseau, and S.K. Kim. 1993. lin-31, a Caenorhabditis elegans HNF-3/fork head transcription factor homolog, specifies three alternative cell fates in vulval development. Genes \& Dev. 7: 933-947.

Miura, N., A. Wanaka, M. Tohyama, and K. Tanaka. 1993. MFH-1, a new member of the fork head domain family, is 
Winnier et al.

expressed in developing mesenchyme. FEBS Lett. 326: 171176.

Neubuser, A., H. Koseki, and R. Balling. 1995. Characterization and developmental expression of $P a x 9$, a paired-box-containing gene related to Pax1. Dev. Biol. 170: 701-716.

Noden, D.M. 1989. Embryonic origins and assembly of blood vessels. Am. Rev. Respir. Dis. 140: 1097-1103.

Norris, W.E., C.D. Stern, and R.J. Keynes. 1989. Molecular differences between the rostral and caudal halves of the sclerotome in the chick embryo. Development 120: 541-548.

Novack, M.J. 1993. Patterns of diversity in the mammalian skull. University of Chicago Press, Chicago, IL.

Olson, E.N. and W.H. Klein. 1994. bHLH factors in muscle development: Dead lines and commitments, what to leave in and what to leave out. Genes \& Dev. 8: 1-8.

Pourquie, O., M. Coltey, C. Breant, and N.M. LeDouarin. 1995. Control of somite patterning from the lateral plate. Proc. Natl. Acad. Sci. 92: 3219-3223.

Pourquie, O., C.-M. Fan, M. Coltey, E. Hirsinger, Y. Watanabe, C. Breant, P. Francis-West, P. Brickell, M. Tessier-Lavigne, and N.M. Le Douarin. 1996. Lateral and axial signals involved in avian somite patterning: A role for BMP-4. Cell 84: 461-471.

Ranscht, B. and M. Bronner-Fraser. 1991. T-cadherin expression alternates with migrating neural crest cells in the trunk of the avian embryo. Development 111: 15-22.

Reaume, A.G., R.A. Conlon, R. Zirngibl, T.P. Yamaguchi, and J. Rossant. 1992. Expression analysis of a Notch homologue in the mouse embryo. Dev. Biol. 154: 377-387.

Sasaki, H. and B.L.M. Hogan. 1993. Differential expression of multiple fork head related genes during gastrulation and axial pattern formation in the mouse embryo. Development 118: 47-59.

Smith, J.L., K.M. Gesteland, and G.C. Schoenwolf. 1994. Prospective fate map of the Mouse primitive streak at 7.5 days of gestation. Dev. Dynam. 201: 279-289.

Soriano, P. 1994. Abnormal kidney development and hematological disorders in PDGF $\beta$-receptor mutant mice. Genes \& Dev. 8: 1888-1896.

Stern, C. and R. Keynes. 1987. Interactions between somite cells: The formation and maintance of segment boundaries in the chick embryo. Development 99: 261-272.

Stoetzel, C., B. Weber, P. Bourgeois, A.L. Bolcato-Bellemin, and F. Perrin-Schmitt. 1995. Dorso-ventral and rostro-caudal sequential expression of $\mathrm{M}$-twist in the postimplantation murine embryos. Mech. Dev. 51: 251-263.

Tam, P.P.L. and P.A. Trainor. 1994. Specification and segmentation of the paraxial mesoderm. Anat. Embryol. 189: 275305.

Theiler, K. 1989. Vertebral malformations. Adv. Anat. Embryol. Cell Biol. 122: 1-99.

Tybulewicz, V.L.J., C.E. Crawford, P.K. Jackson, R.T. Bronson, and R.C. Mulligan. 1991. Neonatal lethality and lymphopenia in mice with a homozygous disruption of the $c$ - $a b l$ protooncogene. Cell 65: 1153-1163.

Verbout, A.J. 1985. The development of the vertebral column. Anat. Embryol. Cell Biol. 89: 1-122.

Wallin, J., J. Wilting, H. Koseki, R. Fritsch, B. Christ, and R. Balling. 1994. The role of $\mathrm{Pax}-1$ in axial skeleton development. Development 120: 1109-1121.

Williams, R., U. Lendahl, and M. Lardelli. 1995. Complementary and combinatorial patterns of Notch gene family expression during early mouse development. Mech. Dev. 53: 357396.

Winnier, G.E., M. Blessing, P.A. Labosky, and B.L.M. Hogan. 1995. Bone morphogenetic protein-4 (BMP-4) is required for mesoderm formation and patterning in the mouse. Genes \& Dev. 9: 2105-2116.

Wolf, C., C. Thisse, C. Stoetzel, B. Thisse, P. Gerlinger, and F. Perrin-Schmitt. 1991. The M-twist gene Mus is expressed in subsets of mesodermal cells and is closely related to the Xenopus X-twi and the Drosophila twist genes. Dev. Biol. 143: 363-373.

Xuan, S., C.A. Baptista, G. Balas, W. Tao, V.C. Soares, and E. Lai. 1995. Winged helix transcription factor BF-1 is essential for the development of the cerebral hemispheres. Neuron 14: 1141-1152.

Zhao, G.-Q., X. Zhou, H. Eberspaecher, M. Solursch, and B. de Crombrugghe. 1993. Cartilage homeoprotein 1, a homeoprotein selectively expressed in chondrocytes. Proc. Natl. Acad. Sci. 90: 8633-8637. 


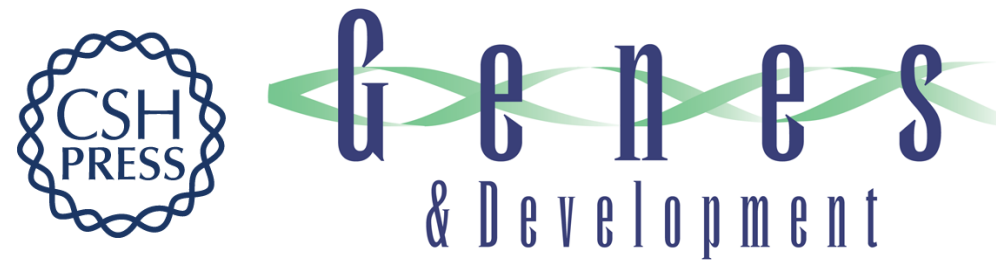

\title{
The winged helix transcription factor MFH1 is required for proliferation and patterning of paraxial mesoderm in the mouse embryo.
}

\author{
G E Winnier, L Hargett and B L Hogan
}

Genes Dev. 1997, 11:

Access the most recent version at doi:10.1101/gad.11.7.926

References This article cites 59 articles, 25 of which can be accessed free at: http://genesdev.cshlp.org/content/11/7/926.full.html\#ref-list-1

License

Email Alerting Service

Receive free email alerts when new articles cite this article - sign up in the box at the top right corner of the article or click here.

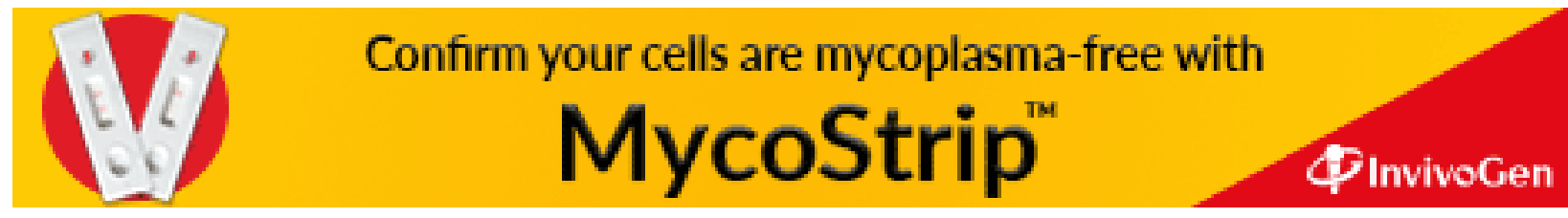

